\title{
NUCLEAR TARGETING OF GOLD NANOPARTICLES
}

\author{
by \\ Celina Yang \\ B.Sc. University of Toronto, 2011 \\ Toronto, Canada
}

\author{
A thesis \\ presented to Ryerson University \\ in partial fulfillment of the \\ requirements for the degree of \\ Master of Science \\ in the Program of \\ Biomedical Physics
}

Toronto, Ontario, Canada, 2014

(C) Celina Yang 2014 


\section{Author's Declaration}

I hereby declare that I am the sole author of this thesis. This is a true copy of the thesis, including any required final revisions as accepted by my examiners.

I authorize Ryerson University to lend this thesis to other institutions or individuals for the purpose of scholarly research.

I further authorize Ryerson University to reproduce this thesis by photocopying or by other means, in total or in part, at the request of other institutions or individuals for the purpose of scholarly research.

I understand that me thesis may be made electronically available to the public.

Celina Yang 


\title{
Abstract
}

\section{Nuclear Targeting of Gold Nanoparticles}

\author{
Celina Yang \\ Master of Science, Biomedical Physics \\ Ryerson University, 2014
}

Gold nanoparticles (GNPs) have been extensively used in cancer research due to their abilities as anti-cancer drug carriers for chemotherapy and as dose enhancers in radiotherapy. Although most GNP research in the past involved cytoplasm localized GNPs, it is predicted that therapy response can be enhanced if GNPs can be effectively targeted into the nucleus. A strategy for designing a GNP-peptide complex for targeting the nucleus will be presented. Three different sequences of peptides (CKKKKKKGGAGDMFG, CGGRKKRRGRRRAP, CALNN) were conjugated onto GNPs. The first peptide was used to stabilize the complex, the second peptide to enhance uptake into the cell, while the third peptide was used to induce nuclear delivery. With nuclear targeting, more damage can be caused to the DNP of cancer cells upon irradiation. This research will establish a more successful NP-based platform that combines treatment modalities and more effectively approach cancer treatment. 


\section{Acknowledgements}

Most importantly, I would like to thank my supervisor, Dr. Devika Chithrani. She has supported and guided me throughout my Masters study. She gave me clear and constructive feedback on my work as well as providing me numerous opportunities to present my work through presentations at conferences or publications. Her passion and drive in research has been a great example for me and her encouragement cultivated my confidence.

I would also like to express my appreciation to my committee members, Dr. Michael Kolios and Dr. Yuan $\mathrm{Xu}$. Despite of their busy schedule, they have guided me throughout my project and their positive words have fueled me to complete this degree. I am fortunate to have strong committee members who greatly helped me expand my knowledge in the field and trusted in my abilities.

It is my pleasure to thank Elizabeth Berndl, Arthur Worthington and my excellent group members: Mehrnoosh Neshatian, Charmainne Cruje and Darren Yohan. I am fortunate to be in a group with excellent teamwork and collaboration skills.

Last but not least I would like to thank my family and friends for their constant support. 


\section{Table of Contents}

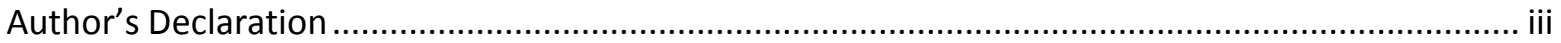

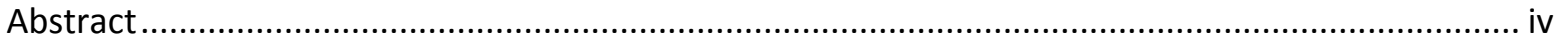

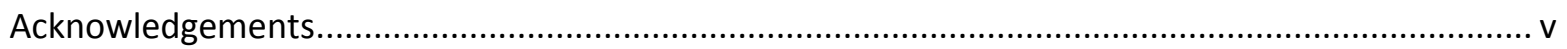

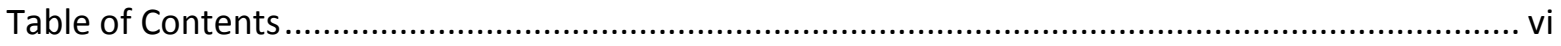

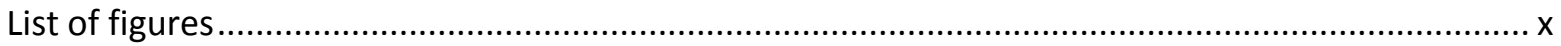

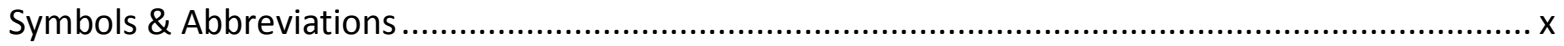

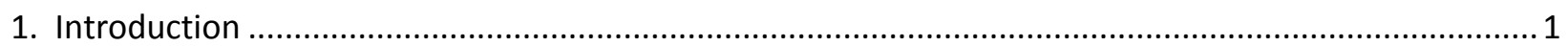

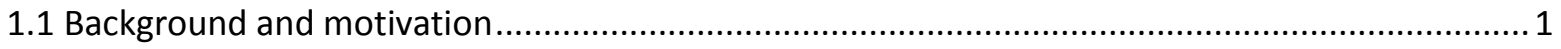

1.2 Gold nanoparticles and the regular pathway in cells ............................................................. 3

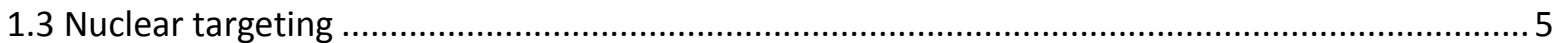

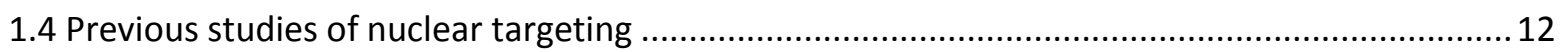

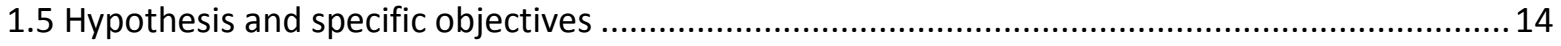

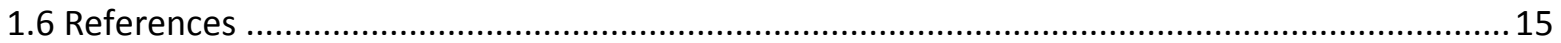

2. Peptide Modified Gold Nanoparticles for Improved Cellular Uptake, Nuclear Transport, and

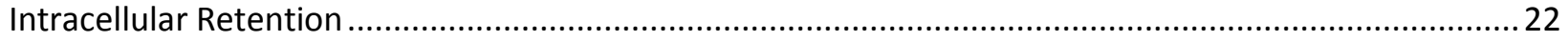

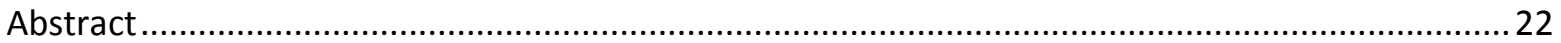

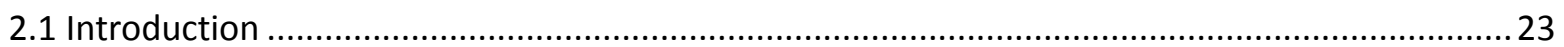

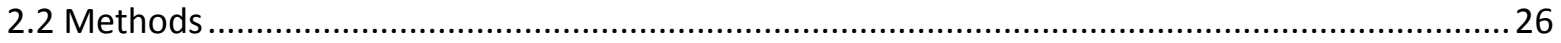

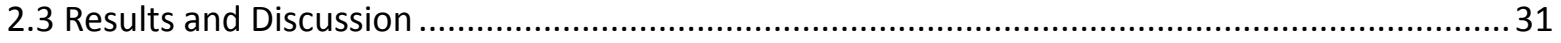

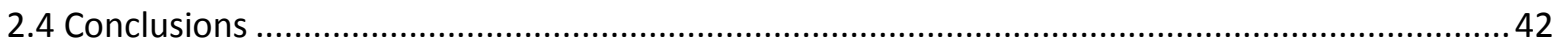

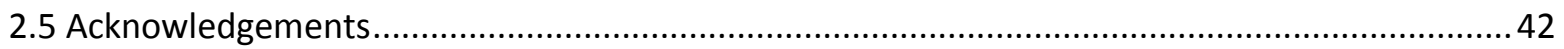

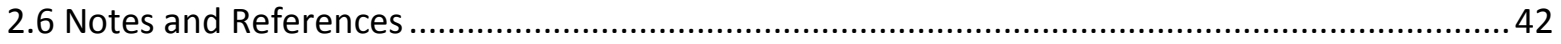

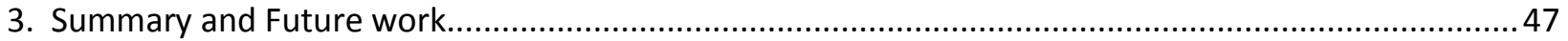

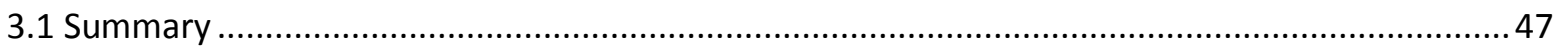

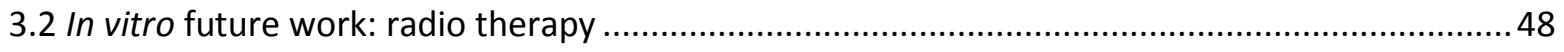

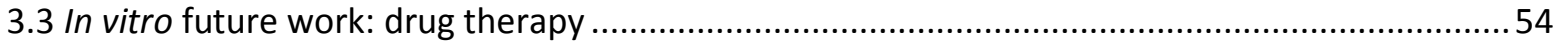

3.4 Combinational radiation and drug therapeutics...................................................................... 58

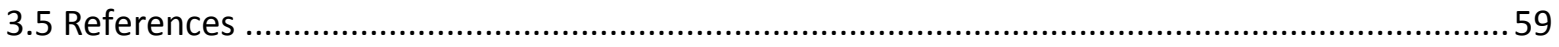




\section{List of figures}

<Fig. 1.1> Regular pathway of untargeted GNPs into the cell. Schematic

illustrating pathway of citrate-capped GNP uptake into the cell. Once GNPs are attached to the receptors on the surface of the cell, membrane invagination occurs followed by budding into the cell, forming a vesicle. The internalized GNPs are sorted inside the vesicle and eventually fuse with lysosomes. GNPs are then excreted out of the cell. This is called the endolyso pathway.

<Fig. 1.2> Pathway of targeted GNPs into the cell. Schematic illustrating pathway of modified GNP uptake into the cell. Once GNPs are internalized into the cell through receptor-mediated endocytosis, the various peptides aid in endosomal escape and transport into the nucleus.

<Fig. 1.3> Structure of CALNN pentapeptide. Molecular structure of CALNN peptide showing cysteine (C) in the N-terminus, Alanine (A) in the second position, Leucine (L) in the third position, and Asparagine (N) in the fourth and fifth position.

<Fig. 1.4> Illustration of a cell, nucleus, and the nuclear pore complex.

The structure of a cell is illustrated (top left), followed by the nucleus (top right) and the nuclear pore structure (bottom).

<Fig. 1.5> Illustration of the mechanism of nuclear entry of GNPs. The structure of a cell is illustrated (top left), followed by the nucleus (top right) and the nuclear pore structure (bottom). 
Schematic of a functionalized GNP used in the study. (B) Trajectory of peptide-conjugated GNPs through the cell. (D-G) Path of the NPs was captured using TEM images and is as follows: (D) GNP-Peptide complex bound to the plasma membrane for entry into the cell via the endocytosis process, $€$ Internalized NPs were localized in vesicles, such as, endosomes and lysosomes, (F) Escaping of NPs from vesicles into the cytoplasm, (G) Entering the nucleus through NPC (scale bars $=100 \mathrm{~nm}$ ).

<Fig. 2.2> Characterization of NPs. (A) TEM image of citrate-capped GNPs. (B) Table presenting the peak wavelength of UV-visible absorption, hydrodynamic radius, and zeta potential of citrate-capped and peptidecapped GNPs. (C) Reflected spectra of GNPs. (D) Darkfield image of GNPs. (scale bars $=100 \mathrm{~nm})$.

<Fig. 2.3> CytoVivaHyperspectral imaging of GNPs internalized in cells. (A) The darkfield image of GNPs in cells. (B) The spectral angle map overlaid onto the hyperspectral darkfield image. The spectrum from each pixel is compared with reflectance spectra from gold, and if a match is determined, the pixels are coloured red. (C) The reflectance spectra from one of the GNPs (white line) and the background reflectance from the nucleus (red line) and the cytoplasm (green line).

<Fig. 2.4> NP uptake data for peptide conjugated GNPs. (A) Cell uptake data corresponding to the presence of each peptide alone and the combined presence of three peptides on GNPs (Error bars represent standard deviation of $n=3$ ). (B) CytoViva Hyperspectral imaging of cells internalized with GNPs functionalized with pentapeptide, NLS, and RGD peptides. The bright dots represent GNPs. The scale bar represents $10 \mu \mathrm{m}$. 
<Fig. 2.5> Mechanism of nuclear transport GNP-peptide complex.

(A) Schematic illustrating the cross-section of the nuclear pore complex. (B)

TEM image showing few nuclear pores in the nuclear membrane. (C) Mechanism of selective nuclear transport. GNP-peptide complexes, which possess a Nuclear Localization Signal (NLS), were bound to importin and were transported through the NPC. Mediators, such as the small GTPase Ran, play a vital role in both the GNP-peptide complex release and the recycling of importin into the cytoplasm through NPC.

<Fig. 2.6> TEM and Hyperspectral imaging of citrate-capped and peptide-GNPs internalized in cells. (A) TEM image of citrate-capped (non-

targeted) GNPs localized in either endosomes or lysosomes. (B) Darkfield image of a cell internalized with non-targeted GNPs. (C) Reflected spectra collected from few GNPs clusters (marked red in image B). (D) TEM image of peptide-capped (nuclear-targeted) GNPs localized in either disrupted endosomes or cytoplasm. (E) Darkfield image of a cell internalized with nuclear-targeted GNPs. (F) Reflected spectra collected from few GNPs clusters (marked red in image E). (Scale bar $=100 \mathrm{~nm})$.

<Fig. 2.7> 2D and 3D view of localization of peptide-capped GNPs within the cell. (A-C) Two dimensional (2D) view of localization of peptide-modified GNPs in the cytoplasm and nucleus using TEM imaging. (A) and (C) are insets of (B). (D-F) Hyperspectral imaging of a cell targeted with peptide-conjugated GNPs. (D) Darkfield image of the cell used for three dimensional (3D) rendering. (E) 3D view of the NPs localized in the cells. Red dots represent GNPs. (F) Nucleus (blue in colour) is added to show the co-localization. (Scale bar $=100 \mathrm{~nm})$. 
<Fig. 2.8> Exocytosis of peptide-capped GNPs. (A) Percent of NPs

exocytosed for cells incubated with citrate-capped and peptide-capped GNPs. (B) Dynamics of exocytosis process following one and six hours (Error bars represent standard deviation of $n=3$ ).

<Fig. 3.1> Improved therapeutics using GNP-peptide complexes. (Top) A clinical machine used to irradiate samples (Bottom) Improved therapeutics (enhanced cell death) of nuclear targeted cells (Error bars represent standard deviation of $n=3$, statistical significance for nuclear targeted cells compared to untargeted and reference cells, $\mathrm{p}<0.05$ ) 


\section{Symbols \& Abbreviations}

BSA - Bovine serum albumin

CPP - Cell penetrating peptide

DLS - Dynamic light scattering

DTT - Dithiothreitol

FBS - Fetal bovine serum

GNP - Gold nanoparticle

ICP-AES - Inductively coupled plasma - Atomic emission spectroscopy

MBS - 3-maleimidobenzoic acid $N$-hydroxysuccinimide ester

NES - Nuclear export sequences

NLS - Nuclear localization signal

NP - Nanoparticle

NPC - Nuclear pore complex

PBS - Phosphate buffered saline

RME - Receptor-medicated endocytosis

SAM - Spectral angle mapping

TEM - Transmission electron microscopy 


\section{Introduction}

\subsection{Background and motivation}

Nanotechnology refers the construction of structures in the nanometer size range, often $100 \mathrm{~nm}$ or smaller, by atomic or molecular level manipulation ${ }^{1}$. Nanoparticles exhibit unique physical and chemical properties that cannot be achieved by other materials ${ }^{2}$. Colloidal gold is one example of nanoparticles with applications in biology and medicine ${ }^{1}$. Among other nanoparticle systems, gold nanoparticles (GNPs) have been used extensively in the field of nanomedicine ${ }^{3}$.

Nanomedicine refers to applications of nanotechnology for treatment, diagnosis, monitoring, and control of biological systems ${ }^{1}$. The term 'nanomedicine', which first appeared in publications in the year 2000, does not have a precise definition due to the blurred borderlines intersecting many scientific disciplines, including biology, chemistry, physics, chemical and mechanical engineering, material science, and clinical science ${ }^{4,5}$. The relatively new trend of encompassing nanotechnology to medicine comes from the recent success in research, which in turn increased funding and awareness to this area ${ }^{5}$. The field of nanomedicine is at an early stage of sharp growth expected to have a high potential in impacting healthcare positively ${ }^{5}$. Nanoparticle-based therapeutic and diagnostic agents have been developed over the last two decades for various diseases, such as cancer, diabetes, pain, asthma, allergy, infections and much more $^{6,7}$. These agents can lead to more effective and convenient routes of administration, decreased toxicity of the treatment, and extend the product life cycle, ultimately reducing health care costs ${ }^{8}$. 
Recent progress in the usage of nanotechnology in medicine has led to the rapid development of novel materials called "nanoparticles (NPs)" for improved therapeutics and imaging in cancer therapy ${ }^{3,9,10}$. Cancer nanotechnology allows and encourages the further development of safer yet more effective diagnostic and therapeutic modalities for cancer therapy 9-12. The ultimate or fundamental goal of nanoparticle (NP)-based platforms will be the successful targeted delivery and monitoring of therapeutics to tumours while causing minimum damage to normal tissue and side effects to the patient ${ }^{13}$. Among other NPs, GNPs are being used cancer research since their size, shape, and surface properties can be tailored easily, they also appear to be biocompatible and have limited toxicity, and they can be used as a radiosensitizer and drug carrier in cancer therapy $y^{3,9,14-16}$. Most of these previous studies were done using nonnuclear targeted GNPs. Gold nanoparticles without modification does not enter the nucleus. The goal of this study was to functionalize GNPs to localize them into the nucleus for improved therapeutic results. Conjugating sequences of peptides onto GNPs for targeting the nucleus is a novel approach to improve therapeutics. Results from this work may be used as a basis in designing NP systems that not only have enhanced cellular uptake, but also targeted the nucleus. 


\subsection{Gold nanoparticles and the regular pathway in cells}

Gold nanoparticles (GNPs) can be synthesized in various sizes $(2-100 \mathrm{~nm})$ and shapes (spheres, rods, stars, etc) and the surface functionalization allows targeting into specific biological structures within the cell ${ }^{17-24}$. Gold Nanoparticles can also be incorporated with polymer- or lipid-based systems such as liposomes, micelles, or dendrimers. This widened the application aspects of GNPs ${ }^{14,19,25-27}$. A number of groups studying GNP cytotoxicity concluded that GNPs are biocompatible ${ }^{28,29}$ which is an important factor for a system to be used in clinical settings.

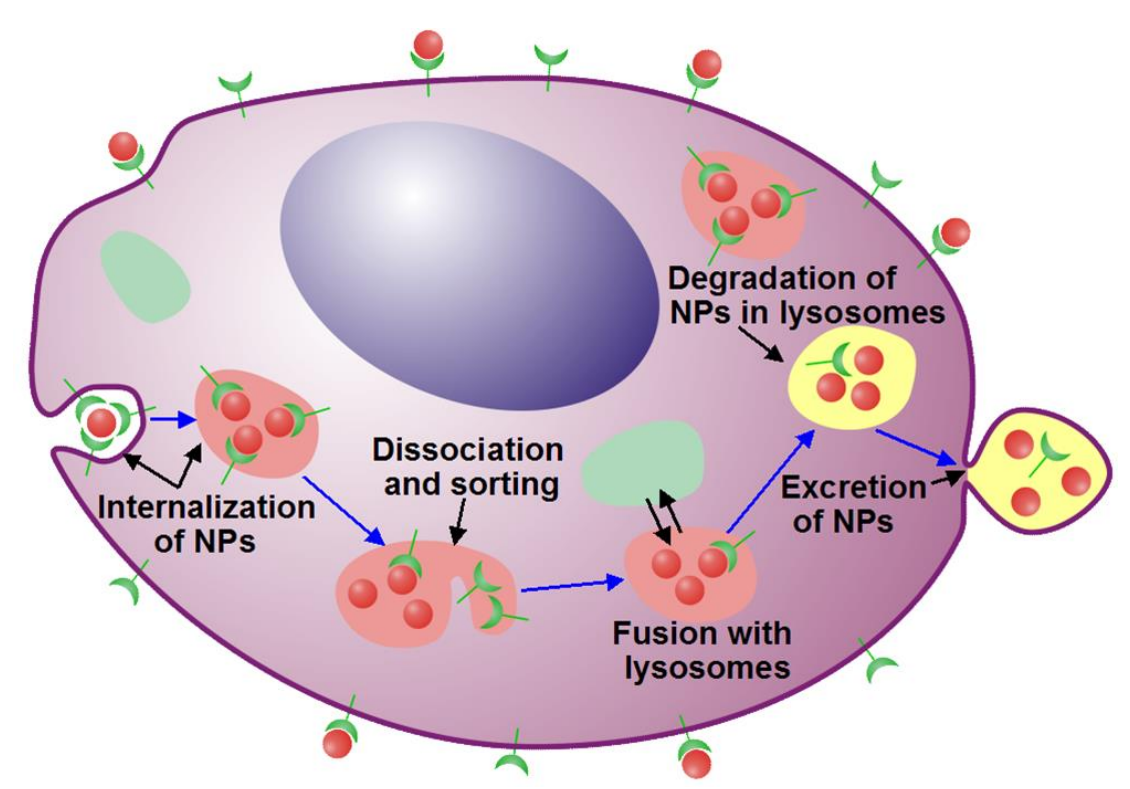

<Fig. 1.1> Regular pathway of untargeted GNPs into the cell. Schematic illustrating pathway of citrate-capped GNP uptake into the cell. Once GNPs are attached to the receptors on the surface of the cell, membrane invagination occurs followed by budding into the cell, forming a vesicle. The internalized GNPs are sorted inside the vesicle and eventually fuse with lysosomes. GNPs are then excreted out of the cell. This is called the endo-lyso pathway. 
The major internalization pathway of untargeted GNPs is confirmed to be receptormediated endocytosis $(\mathrm{RME})^{30-34}$ as the uptake of GNPs decreases in low temperature $\left(4{ }^{\circ} \mathrm{C}\right)$ or other ATP-depleted environments (cells pre-treated with $\left.\mathrm{NaN}_{3}\right)^{32,35-37}$. When GNPs attach to receptors on cell surfaces, the cellular membrane begins to bud inwards followed by the two ends of this compartment pinching off forming a vesicle. Once GNPs are internalized by being trapped in a vesicle, they can be degraded or excreted back to the other side of the plasma membrane along with the receptors ${ }^{38}$. A schematic of the regular pathway of unmodified (citratecapped) GNP is shown in Fig 1.1. 


\subsection{Nuclear targeting}

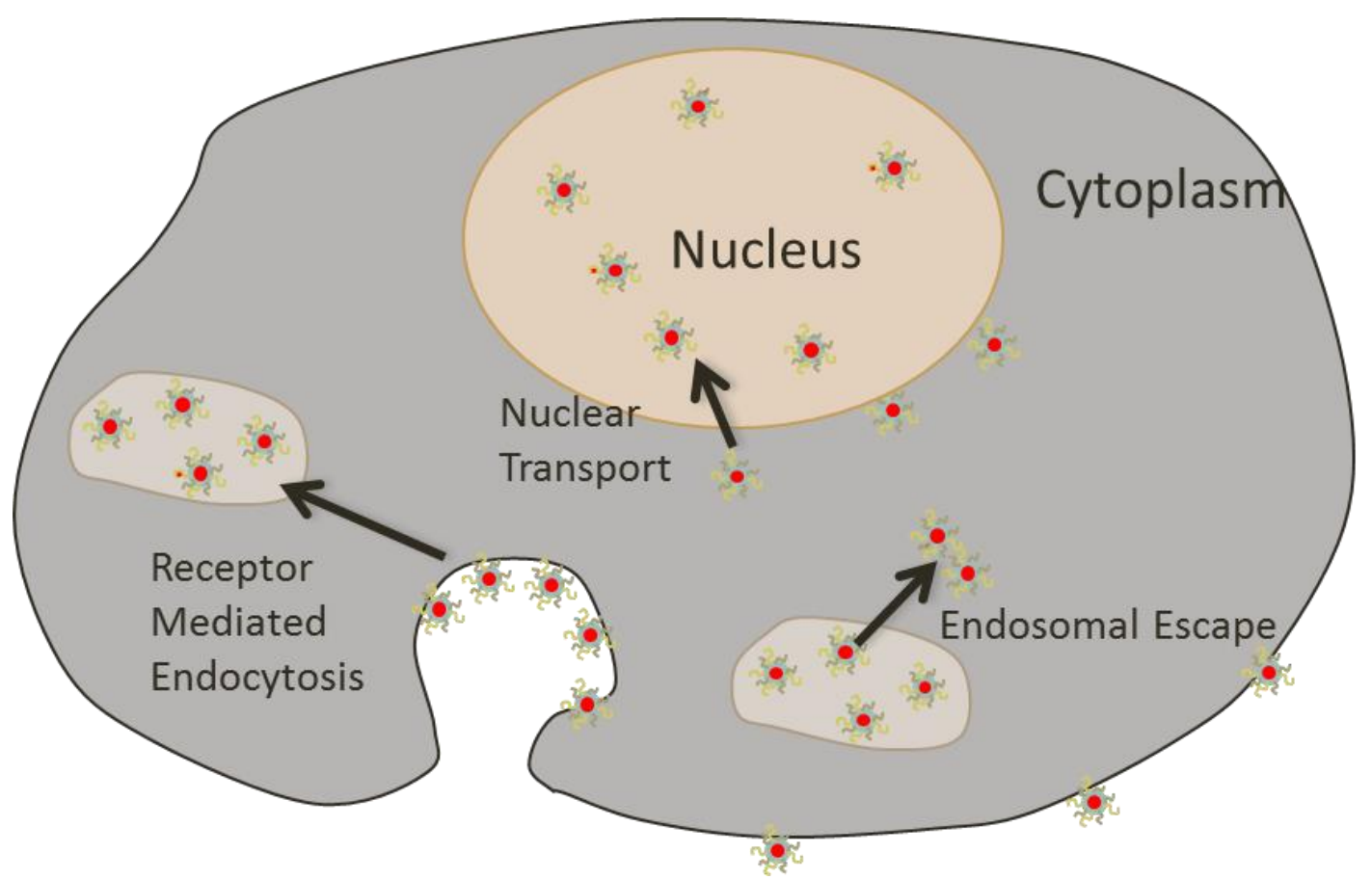

<Fig. 1.2> Pathway of targeted GNPs into the cell. Schematic illustrating pathway of modified GNP uptake into the cell. Once GNPs are internalized into the cell through receptormediated endocytosis, the various peptides aid in endosomal escape and transport into the nucleus.

The nucleus is an important target for nanoparticle applications as genetic information and the transcription machinery of the cell resides in the nucleus. Various therapies that involve nuclear targeting have been used for treatment of diseases, such as gene therapy ${ }^{39}$. However, targeted nuclear delivery is challenging due to the biological barriers - the cellular membrane barrier and the nuclear envelope ${ }^{39,40}$. Most nanomaterials and macromolecules, including gold nanoparticles, require some modifications for nuclear delivery ${ }^{39}$. For targeted nuclear delivery, the particle must at the very least enter the cell, escape endosomal and lysosomal pathways, posess a signal to interact with the nuclear pore complex (NPC), and the whole complex should be small enough (less than $30 \mathrm{~nm}$ ) to cross the nuclear membrane ${ }^{40}$ (see Fig 1.2 and Fig 1.4). 


\subsubsection{Role of peptides}

A mixture of several different peptides sequences can be used to target the nucleus of the cell - each having different functions. The peptides used in this study and those that could be used in the future will be introduced.

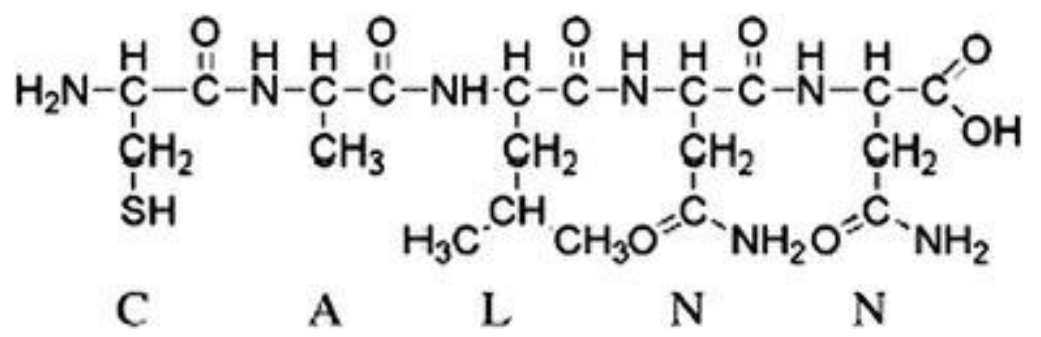

<Fig. 1.3> Structure of CALNN pentapeptide. Molecular structure of CALNN peptide showing cysteine $(\mathrm{C})$ in the N-terminus, Alanine (A) in the second position, Leucine (L) in the third position, and Asparagine $(\mathrm{N})$ in the fourth and fifth position.

A pentapeptide ligand, CALNN, is used to convert citrate-stabilized gold nanoparticles into stable and water-soluble particles ${ }^{41}$. Previously used strategies for stabilization of gold nanoparticles include usage of thiol ligands with hydrophilic terminal groups, such as poly(ethylene glycol) and bovine serum albumin (BSA). Stability problems have been successfully addressed in some approaches but the lack of generic protocols for functionalization of particles with biomolecules remained as a shortcoming ${ }^{41}$. CALNN can be used to synthesize stable gold nanoparticles that are ready to be functionalized with other biomolecules, such as other peptides ${ }^{41}$. Gold nanoparticles, unlike some other naturally occurring proteins, often aggregate in aqueous solutions when thiol-containing amino acids or peptides are added ${ }^{41,42}$. Electrostatic aggregation should also be prevented. This can be achieved by ensuring the particles have a net positive or net negative charge, leading to overall repulsive interactions ${ }^{41}$. 
The thiol group in the side chain of the N-terminal cysteine makes a covalent bond to the surface of the GNP. The alanine and leucine in the second and third position of the sequence possess hydrophobic properties and promotes the self-assembly of the peptide. The leucine is larger than alanine which accounts for the curvature of the spherical nanoparticle. The amide group side chain of the asparagines in the fourth and fifth position possess hydrophilic properties, thus, allowing the CALNN covered GNP complex to be hydrophilic ${ }^{41}$. The structure of CALNN is illustrated in Fig. 1.3.

The arginyl-glycyl-aspartic acid (RGD) tripeptide sequence is found in proteins such as fribronectin, citronectin, and type I collagen ${ }^{43,44}$. These three amino acids form the core structure recognized by cell surface receptors ${ }^{44}$. RGD is known to target alpha $v$ beta 6 integrin proteins which are overexpressed on the surface of most types of cancer cells and enter the cytoplasm through receptor-mediated endocytosis ${ }^{39,45,46}$.

Cell-penetrating peptides (CPP) are another type of peptide sequence that could be used to increase cellular uptake. CPPs are rich in basic amino acids, such as arginine and lysine, and are able to translocate through membranes for cell internalization ${ }^{47}$. The relatively short peptide sequences, which are usually less than 30 amino acids, act as a vector for larger molecules with high efficiency and low toxicity ${ }^{47}$. The mechanism of CPP action is not well understood, but it is currently believed that endocytotic entry followed by endosomal escape is the most common mechanism at a low CPP concentration ${ }^{47}$.

Peptides containing a nuclear localization signal (NLS) have been used for nuclear delivery in several studies ${ }^{48}$. NLS is a sequence of amino acids that mediate the transport of nuclear proteins into the nucleus through the nuclear pore complex and a variety of NLSs are found experimentally ${ }^{49}$. NLSs are generally consisting of a chain of positively charged amino 
acids and these positive residues bind to a type of proteins, called importins ${ }^{49}$. The structure of nuclear pore complexes and the mechanism of nuclear entry will be discussed further in this chapter as well as the next chapter. 


\subsubsection{Nuclear pore complex (NPC)}

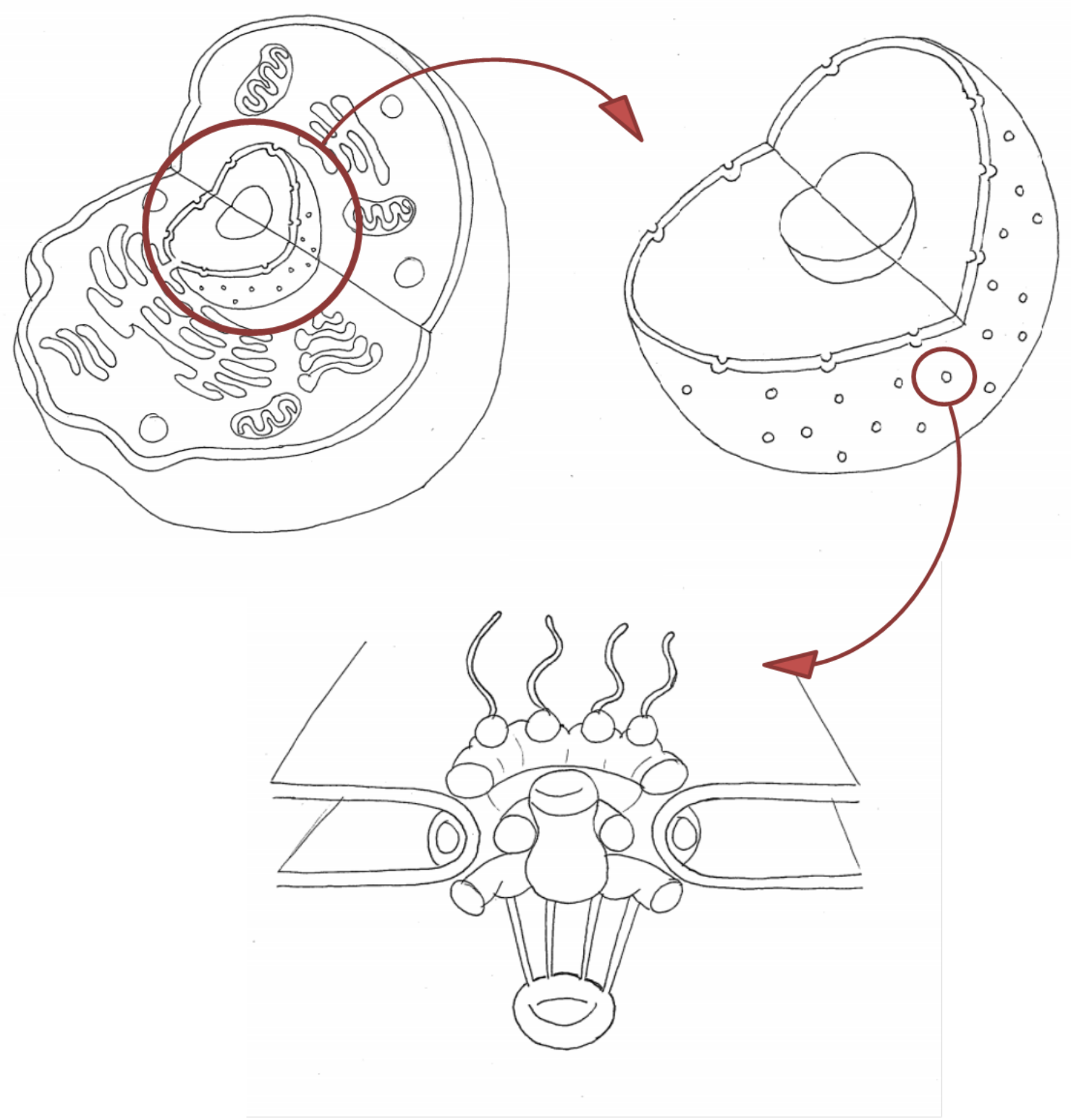

<Fig. 1.4> Illustration of a cell, nucleus, and the nuclear pore complex. The structure of a cell is illustrated (top left), followed by the nucleus (top right) and the nuclear pore structure (bottom).

Understanding the structure of the nuclear pore complex (NPC) is necessary before discussing the mechanism of nuclear entry. The presence of a nucleus is what differentiates 
between a eukaryotic cell from a prokaryotic cell. The nucleoplasm and the genetic material in the nucleus are separated from the cytoplasm by the nuclear envelope, a double membrane layer $^{50,51}$. Nuclear pore complexes are composed of various types of proteins and are embedded throughout the nuclear membrane. NPCs mainly mediate macromolecular transport into and out of the nucleus ${ }^{50,52}$. Although it depends of the activity of the type of cells, the number of NPCs generally varies around $3000-4000$ per nucleus ${ }^{53}$. NPCs are a complex cylindrical structure with octagonal symmetry, $100-150 \mathrm{~nm}$ in diameter ${ }^{51}$. A core structure containing eight spokes surrounding a central tube is present within each NPC and peripheral filaments that are attached to the core form a basket-like structure on the nuclear side of the complex ${ }^{51}$ (see Fig 1.4). Between the eight spokes, there are $10 \mathrm{~nm}$ diameter channels where passive diffusion of ions, water and small proteins less than $60 \mathrm{kDa}$ occur ${ }^{53}$. The transport of larger particles occurs through energy dependent active transport via specific receptor proteins ${ }^{53}$. The pore gate is a dynamic structure and opens up to approximately $30 \mathrm{~nm}^{51,53}$.

The NPC is comprised of layers of interacting proteins, stretching out from the core structure $^{51}$. While some proteins, named nuclear pore complex components or nucleoporins (Nups), form relatively permanent associations with the core structure, others associate transiently with the NPC by constantly cycling on and off or attaching only at particular times in the cell's life cycle ${ }^{51}$. 


\subsubsection{Mechanism of nuclear entry}

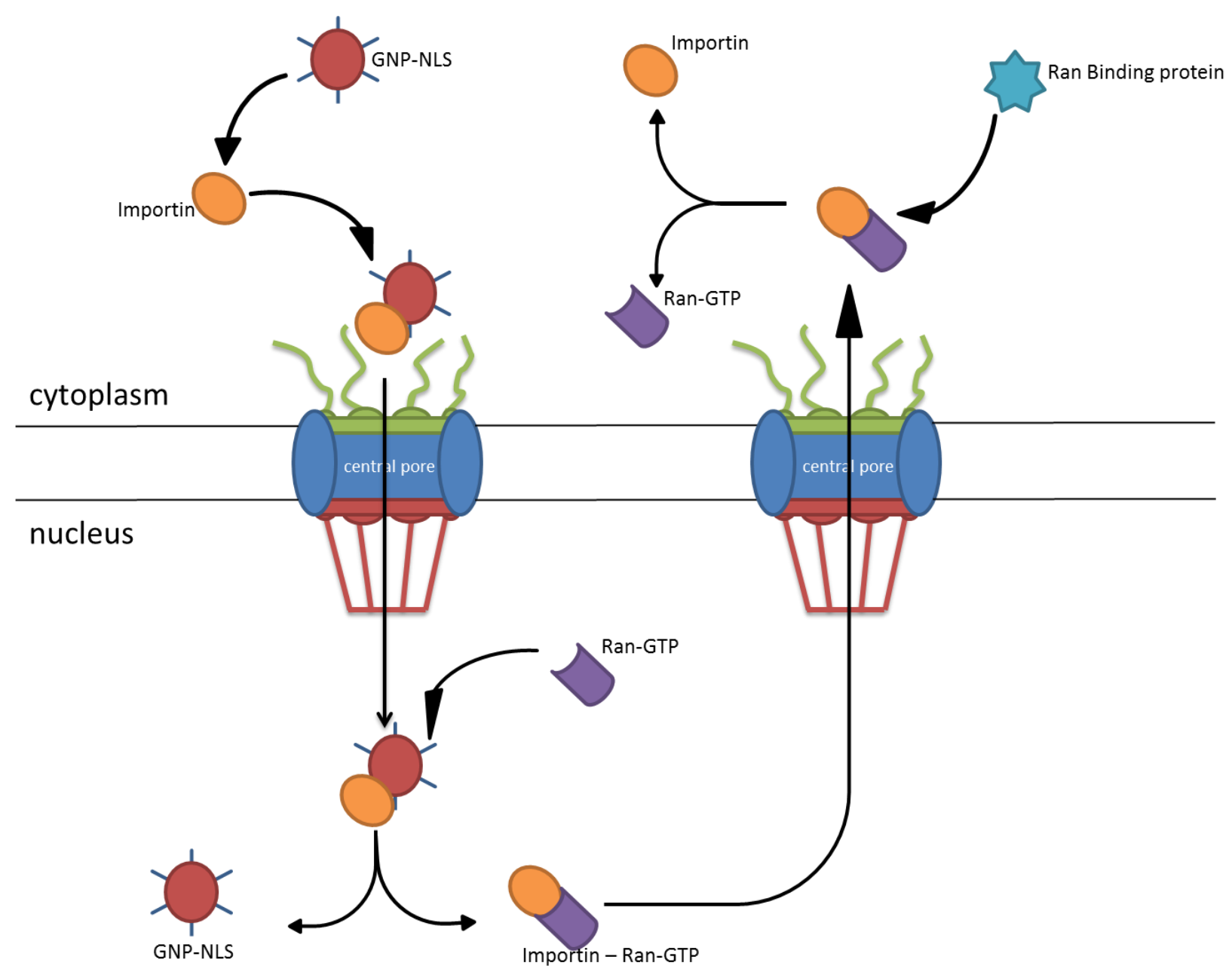

<Fig. 1.5> Illustration of the mechanism of nuclear entry of GNPs. GNPs entering the nucleus carried by importin.

Transport of macromolecules across the NPC require specific amino acid sequence spans, named nuclear localization sequences (NLSs) or nuclear export sequences (NESs) ${ }^{51}$. Karyopherins, such as importins and exportins, are required to bring cargo to the NPC or to modulate translocatio $^{51}$. Karyopherins can bind the cargoes directly or via an adaptor 
$\operatorname{protein}^{51,54,55}$. The importin substrate binds to the importin in the cytoplasm, which then docks to the cytoplasmic periphery of the NPC. The substrate - importin unit is subsequently translocated to the nuclear side of the NPC, mediated by the Ran GDP/GTP cycle ${ }^{54}$. The translocation is terminated on the nuclear side of the NPC which is followed by direct binding of Ran-GTP to importin that causes dissociation between the substrate and the importin ${ }^{54}$. The importin is exported back to the cytoplasm and another protein called the Ran binding protein dissociates the importin and the Ran protein so that the importin can be tagged by another GNP so that the cycle continues $^{51,54}$. The illustration of this mechanism is represented in Fig 1.5.

\subsection{Previous studies of nuclear targeting}

Most studies using nanoparticles have been conducted with particles localizing in the cytoplasm exclusively. However, there are some nuclear targeting studies that involved GNPs in the past. In the early stage, cellular membrane entry was bypassed by using microinjection or modifying the cells chemically ${ }^{\mathbf{5 6}}$. While the GNP-NLS conjugate used in Feldherr's study was translocated to the nucleus upon introduction through microinjection, the complex did not enter the nucleus when the complex was added to the growth media ${ }^{\mathbf{5 6}}$. This suggests that the complex entered the cell through receptor-mediated endocytosis but were not capable of escaping the endo-lyso pathway, hence being trapped in an endosome and not able to enter the nucleus ${ }^{\mathbf{4 0}}$. Other groups have used different complexes to overcome this problem. Tkachenko et al. modified $20 \mathrm{~nm}$ GNPs by covering the surface with peptide-conjugated BSA ${ }^{\mathbf{4 0}}$. Various NLS and RME peptides were used. This group found that two shorter sequences of peptides were more efficient in GNP transportation into the nucleus compared to one long sequence ${ }^{\mathbf{4 0}}$. The reason 
behind the difference in efficiency was suspected to be structural or spatial. The peptides were found to be in an extended form, therefore, having two shorter sequences increased the probability of individual targeting signals to be more accessible to the appropriate cellular receptors ${ }^{40}$.

Qian et al. and Kang et al. used sequential conjugation of Poly (ethylene glycol), PEG 5000, RGD and NLS peptides onto the GNP surface with the exclusion of other proteins, such as BSA ${ }^{39,46}$. PEGylation was done to prevent aggregation of NPs upon exposure to oppositely charged peptides by generating steric repulsion, to stabilize GNPs in a physiological environment, and to minimize nonspecific cellular uptake. PEG being a hydrophilic polymer minimizes nonspecific interactions in biological systems. A similar system is proposed in this manuscript using a pentapeptide in lieu of PEG. 


\subsection{Hypothesis and specific objectives}

This study is based on the hypothesis that incubating spherical GNPs conjugated with specific peptide sequences will increase uptake and improve cellular retention and targeting into the nucleus of the cell. To test the hypothesis, HeLa cervical cancer cells were incubated with peptide-conjugated GNPs and irradiation was performed to observe if therapeutic results are improved compared to the control sample.

The specific objectives are:

- To visually observe whether conjugated GNPs enter the nucleus of the cell using microscopic techniques

- To determine the increase in cellular uptake and improvement in intracellular retention through quantification measurements 


\subsection{References}

1. Moghimi SM, Hunter AC, Murray JC. Nanomedicine: Current status and future prospects. FASEB J. 2005;19(3):311-330.

2. Baltzer N, Copponnex T. Precious metals for biomedical applications. Elsevier Woodhead publishing; 2014.

3. Chithrani DB. Optimization of bio-nano interface using gold nanostructures as a model nanoparticle system. Insciences $J$. 2011;1(3):115-135.

4. Wagner V, Dullaart A, Bock AK, Zweck A. The emerging nanomedicine landscape. Nat Biotechnol. 2006;24(10):1211-1217.

5. Farokhzad OC, Langer R. Nanomedicine: Developing smarter therapeutic and diagnostic modalities. Adv Drug Deliv Rev. 2006;58(14):1456-1459.

6. Kawasaki ES, Player A. Nanotechnology, nanomedicine, and the development of new, effective therapies for cancer. Nanomedicine. 2005;1(2):101-109.

7. Brannon-Peppas L, Blanchette JO. Nanoparticle and targeted systems for cancer therapy. Adv Drug Deliv Rev. 2004;56(11):1649-1659.

8. Zhang L, Gu FX, Chan JM, Wang AZ, Langer RS, Farokhzad OC. Nanoparticles in medicine: Therapeutic applications and developments. Clin Pharmacol Ther. 2008;83(5):761-769.

9. Jelveh S, Chithrani DB. Gold nanostructures as a platform for combinational therapy in future cancer therapeutics. Cancers. 2011;3(1):1081-1110. 
10. Chithrani DB. Intracellular uptake, transport, and processing of gold nanostructures. Mol Membr Biol. 2010;27(7):299-311.

11. Cuenca AG, Jiang H, Hochwald SN, Delano M, Cance WG, Grobmyer SR. Emerging implications of nanotechnology on cancer diagnostics and therapeutics. Cancer. 2006;107(3):459-466.

12. Rao J. Shedding light on tumors using nanoparticles. ACS nano. 2008;2(10):1984-1986.

13. Perrault SD, Walkey C, Jennings T, Fischer HC, Chan WC. Mediating tumor targeting efficiency of nanoparticles through design. Nano lett. 2009;9(5):1909-1915.

14. Chithrani DB, Jelveh S, Jalali F, et al. Gold nanoparticles as radiation sensitizers in cancer therapy. Radiat Res. 2010;173(6):719-728.

15. Bergen JM, Von Recum HA, Goodman TT, Massey AP, Pun SH. Gold nanoparticles as a versatile platform for optimizing physicochemical parameters for targeted drug delivery. Macromolecular bioscience. 2006;6(7):506-516.

16. Shukla R, Bansal V, Chaudhary M, Basu A, Bhonde RR, Sastry M. Biocompatibility of gold nanoparticles and their endocytotic fate inside the cellular compartment: A microscopic overview. Langmuir. 2005;21(23):10644-10654.

17. Souza GR, Christianson DR, Staquicini FI, et al. Networks of gold nanoparticles and bacteriophage as biological sensors and cell-targeting agents. Proc Natl Acad Sci U SA. 2006;103(5):1215-1220. 
18. Tkachenko AG, Xie H, Liu Y, et al. Cellular trajectories of peptide-modified gold particle complexes: Comparison of nuclear localization signals and peptide transduction domains. Bioconjug Chem. 2004;15(3):482-490.

19. Park SH, Oh SG, Mun JY, Han SS. Loading of gold nanoparticles inside the DPPC bilayers of liposome and their effects on membrane fluidities. Colloids Surf B Biointerfaces. 2006;48(2):112-118.

20. Nativo P, Prior IA, Brust M. Uptake and intracellular fate of surface-modified gold nanoparticles. ACS Nano. 2008;2(8):1639-1644.

21. Berry CC, de la Fuente JM, Mullin M, Chu SW, Curtis AS. Nuclear localization of HIV-1 tat functionalized gold nanoparticles. IEEE Trans Nanobioscience. 2007;6(4):262-269.

22. Chen PC, Mwakwari SC, Oyelere AK. Gold nanoparticles: From nanomedicine to nanosensing. Nanotechnol Sci Appl. 2008;1:45-65.

23. Jiang W, Kim BYS, Rutka JT., Chan WCW. Nanoparticle-mediated cellular response is sizedependent. Nat nanotechnol. 2008;3:145-150.

24. Feldherr CM, Kallenbach E, Schultz N. Movement of a karyophilic protein through the nuclear pores of oocytes. J Cell Biol. 1984;99(6):2216-2222.

25. Garcia ME, Baker LA, Crooks RM. Preparation and characterization of dendrimer-gold colloid nanocomposites. Anal Chem. 1999;71(1):256-258. 
26. Mohamed MB., Ismail KZ., Link S, El-Sayed MA. Thermal reshaping of gold nanorods in micelles. J. of Phys Chem B. 1998;102(47):9370-9374.

27. Carrot G., Valmalette JC, Plummer CJG et al. Gold nanoparticle synthesis in graft copolymer micelles. Colloid polym sci. 1998;276(10):853-859.

28. Shukla R, Bansal V, Chaudhary M, Basu A, Bhonde RR, Sastry M. Biocompatibility of gold nanoparticles and their endocytotic fate inside the cellular compartment: A microscopic overview. Langmuir. 2005;21(23):10644-10654.

29. Connor EE, Mwamuka J, Gole A, Murphy CJ, Wyatt MD. Gold nanoparticles are taken up by human cells but do not cause acute cytotoxicity. Small. 2005;1(3):325-327.

30. Chithrani BD, Ghazani AA, Chan WC. Determining the size and shape dependence of gold nanoparticle uptake into mammalian cells. Nano Lett. 2006;6(4):662-668.

31. Kirchhausen T. Three ways to make a vesicle. Nat Rev Mol Cell Biol. 2000;1(3):187-198.

32. Kam NW, Liu Z, Dai H. Carbon nanotubes as intracellular transporters for proteins and DNA: An investigation of the uptake mechanism and pathway. Angew Chem Int Ed Engl. 2006;45(4):577-581.

33. Mukherjee S, Ghosh RN, Maxfield FR. Endocytosis. Physiol Rev. 1997;77(3):759-803.

34. Jin H, Heller DA, Sharma R, Strano MS. Size-dependent cellular uptake and expulsion of single-walled carbon nanotubes: Single particle tracking and a generic uptake model for nanoparticles. ACS Nano. 2009;3(1):149-158. 
35. Chithrani BD, Chan WC. Elucidating the mechanism of cellular uptake and removal of protein-coated gold nanoparticles of different sizes and shapes. Nano Lett. 2007;7(6):1542-1550.

36. Schroter CJ, Braun M, Englert J, Beck H, Schmid H, Kalbacher H. A rapid method to separate endosomes from lysosomal contents using differential centrifugation and hypotonic lysis of lysosomes. J Immunol Methods. 1999;227(1-2):161-168.

37. Silverstein SC, Steinman RM, Cohn ZA. Endocytosis. Annu Rev Biochem. 1977;46:669-722.

38. Alberts B, Bray D, Lewis J, Raff M, Roberts K, Watson JD. Molecular biology of the cell, 1994. Garland, New York. 139-194.

39. Qian W, Curry T, Che Y, Kopelman R. Targeted delivery of peptide-conjugated biocompatible gold nanoparticles into cancer cell nucleus. SPIE . 2013:85951D-85951D-8.

40. Tkachenko AG, Xie H, Coleman D, et al. Multifunctional gold nanoparticle-peptide complexes for nuclear targeting. J Am Chem Soc. 2003;125(16):4700-4701.

41. Lévy R, Thanh NT, Doty RC, et al. Rational and combinatorial design of peptide capping ligands for gold nanoparticles. J Am Chem Soc. 2004;126(32):10076-10084.

42. Pengo P, Broxterman QB, Kaptein B, Pasquato L, Scrimin P. Synthesis of a stable helical peptide and grafting on gold nanoparticles. Langmuir. 2003;19(6):2521-2524.

43. D'Souza SE, Ginsberg MH, Plow EF. Arginyl-glycyl-aspartic acid (RGD): A cell adhesion motif. Trends Biochem Sci. 1991;16:246-250. 
44. Gehlsen KR, Argraves WS, Pierschbacher MD, Ruoslahti E. Inhibition of in vitro tumor cell invasion by arg-gly-asp-containing synthetic peptides. J Cell Biol. 1988;106(3):925-930.

45. Gao H, Shi W, Freund LB. Mechanics of receptor-mediated endocytosis. Proc Natl Acad Sci U S A. 2005;102(27):9469-9474.

46. Kang B, Mackey MA, El-Sayed MA. Nuclear targeting of gold nanoparticles in cancer cells induces DNA damage, causing cytokinesis arrest and apoptosis. J Am Chem Soc. 2010;132(5):1517-1519.

47. Madani F, Lindberg S, Langel U, Futaki S, Graslund A. Mechanisms of cellular uptake of cell-penetrating peptides. J Biophys. 2011;2011:414729.

48. Simeoni F, Morris MC, Heitz F, Divita G. Insight into the mechanism of the peptide-based gene delivery system MPG: Implications for delivery of siRNA into mammalian cells. Nucleic Acids Res. 2003;31(11):2717-2724.

49. Cokol M, Nair R, Rost B. Finding nuclear localization signals. EMBO Rep. 2000;1(5):411415.

50. Fernandez-Martinez J, Rout MP. Nuclear pore complex biogenesis. Curr Opin Cell Biol. 2009;21(4):603-612.

51. Wente SR, Rout MP. The nuclear pore complex and nuclear transport. Cold Spring Harbor perspectives in biology. 2010;2(10):a000562-a000562. 
52. Suntharalingam M, Wente SR. Peering through the pore: Nuclear pore complex structure, assembly, and function. Developmental cell. 2003;4(6):775-789.

53. Pavelka M, Roth J. Nuclear pore complexes. In: Vienna: Springer Vienna; 2010:16-17.

10.1007/978-3-211-99390-3_9.

54. Görlich D. Nuclear protein import. Curr Opin Cell Biol. 1997;9(3):412-419.

55. Pemberton LF, Paschal BM. Mechanisms of receptor-mediated nuclear import and nuclear export. Traffic. 2005;6(3):187-198.

56. Feldherr CM, Akin D. The permeability of the nuclear envelope in dividing and nondividing cell cultures. J Cell Biol. 1990;111(1):1-8. 


\title{
2. Peptide Modified Gold Nanoparticles for Improved Cellular Uptake, Nuclear Transport, and Intracellular Retention
}

\author{
C. Yang, ${ }^{a}{ }^{J}$. Uertz, ${ }^{b}$ D. Yohan, ${ }^{a}$ and B. D. Chithrani ${ }^{a}$ *
}

\begin{abstract}
Gold nanoparticles (GNPs) are being extensively used in cancer therapeutic applications due to their ability to act as both an anticancer drug carrier in chemotherapy and as a dose enhancer in radiotherapy. The therapeutic response can be further enhanced if nanoparticles (NPs) can be effectively targeted into the nucleus. Here, we present an uptake and removal of GNPs functionalized with three peptides. The first peptide (RGD peptide) enhanced the uptake, the second peptide (NLS peptide) enhanced the nuclear delivery, while the third one (pentapeptide) covered the rest of the surface and protected it from the binding of serum proteins onto the NP surface. The pentapeptide also stabilized the conjugated GNP complex. The peptide-capped GNPs showed a five-fold increase in NP uptake followed by effective nuclear localization. The fraction of NPs exocytosed was less for peptide-capped NPs as compared to citrate-capped ones. Enhanced uptake and prolonged intracellular retention of peptide-capped GNPs could allow NPs to perform their desired applications more efficiently in cells. These studies will provide guidelines for developing NPs for therapeutic applications, which will require "controlling" the NP accumulation rate while maintaining low toxicity.
\end{abstract}




\subsection{Introduction}

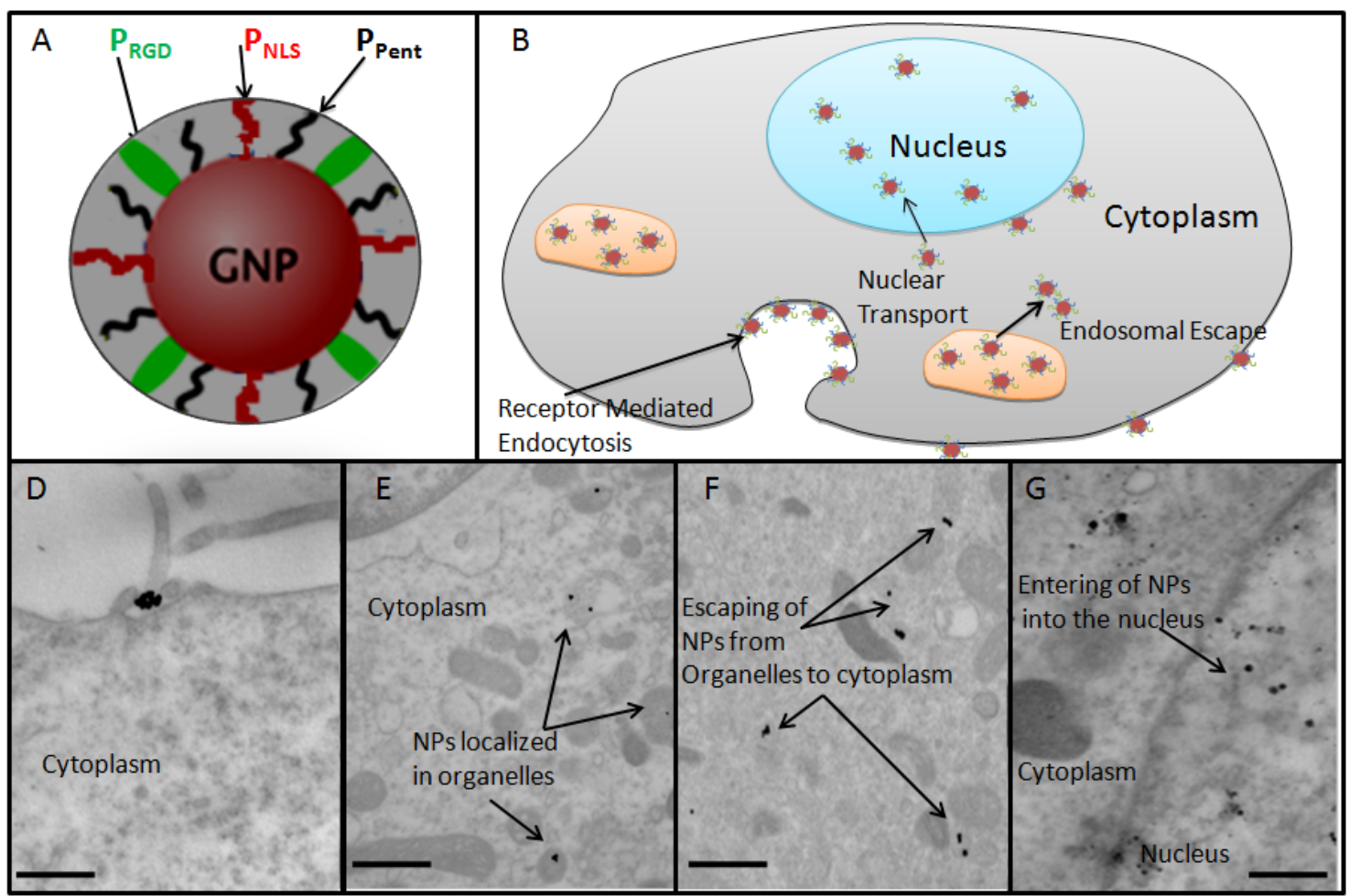

<Fig. 2.1> Trajectory of peptide-conjugated GNPs through the cell. (A) Schematic of a functionalized GNP used in the study. (B) Trajectory of peptide-conjugated GNPs through the cell. (D-G) Path of the NPs was captured using TEM images and is as follows: (D) GNP-Peptide complex bound to the plasma membrane for entry into the cell via the endocytosis process, $(\mathrm{E})$ Internalized NPs were localized in vesicles, such as, endosomes and lysosomes, (F) Escaping of NPs from vesicles into the cytoplasm, $(G)$ Entering the nucleus through NPC (scale bars $=100$ $\mathrm{nm})$.

Nanotechnology-based approaches facilitate the further development of safer yet more effective diagnostic and therapeutic modalities for cancer therapy ${ }^{1-5}$. The primary goal of nanoparticle (NP)-based platforms will be the optimized delivery of therapeutics to tumours while causing minimum damage to normal tissue and side effects to the patient ${ }^{6-10}$. Among other NPs, Gold NPs (GNPs) are being used in cancer research due to their biocompatibility and ability to act as a radiosensitizer and as a drug carrier in cancer therapy ${ }^{3,4,11-13}$. The design of 
smart multifunctional nanocarriers in order to improve current therapeutic applications requires a thorough understanding of the mechanisms behind nanoparticles (NPs) entering and leaving the cells. For drug delivery and radiation therapy applications, it is necessary to control and manipulate the accumulation of NPs for an extended period of time within the cell. Previous studies have shown that both uptake and removal mechanisms are dependent on the size, shape, and surface properties of NPs. Among NP sizes between 13-100 nm, NPs of diameter $50 \mathrm{~nm}$ showed the highest cell uptake ${ }^{11,14-16}$. Elucidating the mechanism of uptake and removal of NPs in cells could lead to a better understanding of NP toxicity. For example, if the NPs are trapped in vesicles and leave the cells intact, they are unlikely to induce cellular toxicity). Many theoretical calculations support the size dependent NP uptake ${ }^{17-19}$. Chithrani et al. have put forward a theoretical calculation to support the NP removal process ${ }^{15}$. In most of these studies, NPs took the endo-lyso path where NPs enter the cell through endocytosis, are trapped in endosomes, fuse with lysosomes for processing, and leave the cell via the exocytosis process. During the endo-lyso path, NPs were localized in either endosomes or lysosomes. Cell cytoplasm and nucleus were free of NPs. Recent studies have shown enhanced therapeutic effects when NPs were targeted into the nucleus ${ }^{20}$. Several approaches have been used for successful nuclear targeting of NPs as discussed in the next section ${ }^{21-26}$. For successful targeted nuclear delivery, the NPs must escape endosomal pathways, and interact with the Nuclear Pore Complex (NPC) for entry into the nucleus as illustrated in $\langle$ Fig. 2.1 $\rangle$. Furthermore, the NPs should be small enough to cross the nuclear membrane $(<30 \mathrm{~nm} \text { for import through nuclear pores })^{27}$. In the past, scientists have used viruses to deliver genes to cell nuclei. There have been limited studies using NP-based non-viral vectors for targeting into the nucleus via peptide sequences derived from viruses $^{21,24,28,29}$. However, many of the peptides used on these non-viral vectors were more 
efficient on either cell entry or nuclear entry. Previous studies have shown that the combination of natural peptide sequences derived from viruses would be more effective as opposed to using a single peptide ${ }^{20,21,30}$. Multiple peptides were first assembled on a Bovine Serum Albumin (BSA) molecule followed by conjugation of BSA onto NP surface. This is a multi-step process which requires the purification of NPs through gel columns to remove reactants such as 3maleimidobenzoic acid $N$-hydroxysuccinimide ester (MBS) and Dithiothreitol (DTT). In this study, we have shown how to assemble multiple peptides on the surface of GNPs using a twostep process. The cellular uptake and removal of peptide-conjugated NPs were also discussed using both quantitative and qualitative methods.

In this study, a combination of a natural peptide (derived from a virus) and two synthetic peptides on the same NPs were used. The synthetic peptide $\left(\mathrm{P}_{\mathrm{RGD}}\right)$ contains a segment of basic lysine residues in addition to the integrin-binding domain (RGD) (peptide sequence: H-Cys-LysLys-Lys-Lys-Lys-Lys-Gly-Gly-Arg-Gly-Asp-Met-Phe-Gly-OH). The lysine residues were added to mimic NLS peptides while the integrin-binding domain was employed to enhance cell entry. The integrins are a family of the transmembrane glycoproteins used by a number of viruses for the purpose of cell internalization ${ }^{31}$. This type of peptide is also referred to as a RME (receptor mediated endocytosis) peptide due to the enhanced cell delivery of NPs via the RME process ${ }^{21}$. However, it is also possible to avoid the RME process by using cell penetrating peptides $(\mathrm{CPPs})^{25}$. Brust and co-workers suggested the approach of evading the well-established endosomal pathway of uptake to a significant extent, either via the delivery of the NPs by liposomes or by surface modification of the NPs with the supposed cell penetrating peptides $(\mathrm{CPPs})^{25}$. However, the role of CPPs is not fully understood yet. The second peptide used in our study is a natural peptide $\left(\mathrm{P}_{\mathrm{NLS}}\right)$, and has a nuclear localization signal (NLS) to facilitate nuclear 
entry. The sequence (H-Cys-Gly-Gly-Arg-Lys-Lys-Arg-Arg-Gln-Arg-Arg-Arg-Ala-Pro-OH) of $\mathrm{P}_{\mathrm{NLS}}$ peptide originated from an adenovirus. The third peptide known as "pentapeptide ( $\left.\mathrm{P}_{\text {Pent }}\right)$ " (Sequence: H-Cys-Ala-Leu-Asn-Asn-OH) was used to protect the NPs against serum proteins. It was also employed to stabilize NPs for conjugation of the previously discussed peptides.

\subsection{Methods}

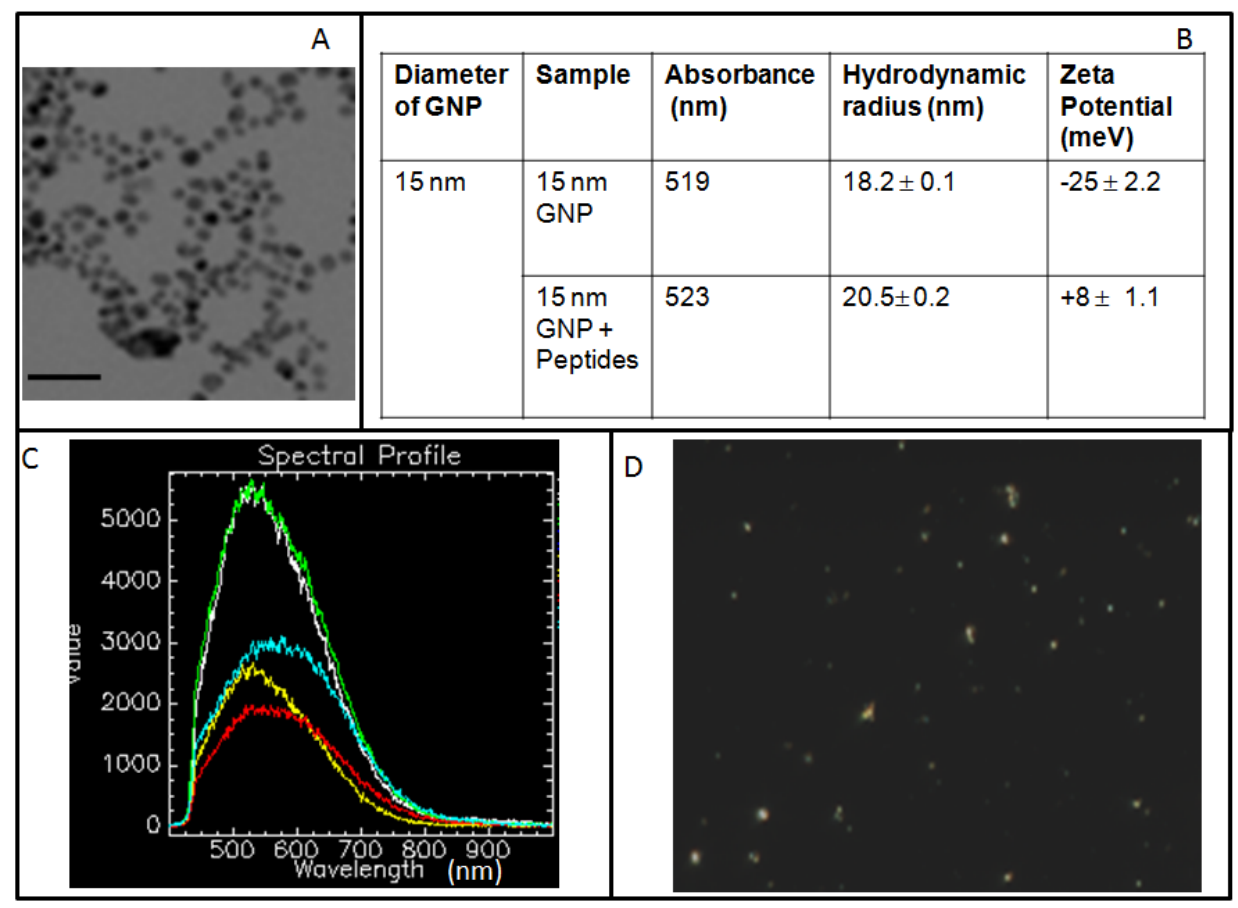

<Fig. 2.2> Characterization of NPs. (A) TEM image of citrate-capped GNPs (scale bar $=$ 100nm). (B) Table presenting the peak wavelength of UV-visible absorption, hydrodynamic radius, and zeta potential of citrate-capped and peptide-capped GNPs. (C) Reflected spectra of GNPs. (D) Darkfield image of GNPs. 


\subsubsection{Synthesis of GNPs}

GNPs of size $15 \mathrm{~nm}$ were synthesized using the citrate reduction method ${ }^{32,33}$. First, $300 \mathrm{ml}$ of $1 \% \mathrm{HAuCl}_{4} \cdot 3 \mathrm{H}_{2} \mathrm{O}$ (Sigma-Aldrich) was added to $30 \mathrm{ml}$ of double-distilled water and heated on a hot plate while stirring. Once it reached the boiling point, $600 \mu 1$ of $1 \%$ anhydrous citric acid (Sigma-Aldrich) was added to form NPs $14 \mathrm{~nm}$ in diameter. After the color of the solution changed from dark blue to red, the solution was left to boil for another five minutes while stirring. Finally, the GNP solution was brought to room temperature while being stirring.

\subsubsection{Peptide-GNP complex preparation}

Peptide-GNP complexes were assembled by first conjugating the GNPs with H-Cys-AlaLeu-Asn-Asn-OH $\left(\mathrm{P}_{\text {Pent }}\right)$ with approximately 300 peptides/GNP ratio for stabilization purposes. Following this, the peptide ( $\mathrm{P}_{\mathrm{RGD}-\mathrm{NLS}}$ ) with H-Cys-Lys-Lys-Lys-Lys-Lys-Lys-Gly-Gly-Arg-GlyAsp-Met-Phe-Gly-OH sequence was added with an 8 to 10 peptide/GNP ratio. For nuclear targeted GNPs, $\mathrm{P}_{\mathrm{RGD}}$ and $\mathrm{P}_{\mathrm{NLS}}$ peptides (H-Cys-Gly-Gly-Arg-Lys-Lys-Arg-Arg-Gln-Arg-ArgArg-Ala-Pro-OH) were added in a 1:1 ratio.

\subsubsection{Characterization of NPs}

Nanoparticles were characterized using TEM, Dynamic Light Scattering (DLS), zeta potential measurements, and using optical reflectance as illustrated in Fig. 2.2. TEM images showed that the diameter of the NPs were approximately $15 \mathrm{~nm}$. Zeta potential measurements displayed that naked or non-conjugated NPs were negatively charged while the peptide conjugated NPs were positively charged. GNPs have a strong reflectance spectrum (Fig. 2.2 C) and were able to image (Fig. 2.2 D) using this property. 


\subsubsection{Cell Culture and Particle Delivery}

HeLa (cervical cancer cell line) cells were cultured in Dulbecco's Modified Eagle's Medium (DMEM) supplemented with 10\% Fetal Bovine Serum (FBS). For optical imaging purposes, the cells were placed on glass coverslips, grown to $75 \%$ confluency, and then incubated with NP conjugates $(10 \mathrm{nM})$ for six hours. Following the incubation, the coverslips were rinsed extensively with Phosphate-Buffered Saline (PBS). Subsequently, the cells were fixed with 4\% paraformaldehyde in PBS for $15 \mathrm{~min}$ at room temperature and then rehydrated in PBS. Following fixation, the cover slip with cells were mounted onto glass slides and allowed to dry overnight prior to microscopy analysis.

\subsubsection{Quantification of NP uptake and removal}

To quantify NP uptake, following eight hours of incubation with GNPs, the cells were washed three times with PBS and trypsinized for quantification of GNPs present per cell. Cells were counted and then treated with $\mathrm{HNO}_{3}$ at $200^{\circ} \mathrm{C}$ in an oil bath for ICP-AES analysis. To quantify NP removal, cells pre-incubated with NPs for eight hours were washed with PBS three times, introduced to fresh media supplemented with FBS, and left in the incubator for monitoring the exocytosis process. After one and six hour time points, the cell were rinsed three times with PBS and trypsinized for quantification of GNPs present per cell.

\subsubsection{CytoViva Analysis of Cells with Internalized NPs}

This CytoViva technology (Auburn, USA) was specifically designed for optical observation and spectral confirmation of NPs as they interact with cells and tissues. The illumination of the microscope system utilizes oblique angle lighting to create high signal-to-noise optimized darkfield based images. $\langle$ Fig. 2.3A $\rangle$ is a darkfield image of a group of cells with internalized 
GNPs. The GNPs appear bright owing to their high scattering cross-section. With the integrated CytoViva hyperspectral imaging capability, reflectance spectra from specific materials can be captured and measured. The SAM (Spectral Angle Mapping) is an automated procedure used to determine whether GNPs are present in the input image, and locates which pixels contain the material of interest. SAM accomplishes these tasks by comparing unknown spectra in hyperspectral imagery with known spectra for the material of interest (GNPs in this case). The hyperspectral image displays the relative degree to which unknown spectra in each image pixel match the known GNP spectrum. 


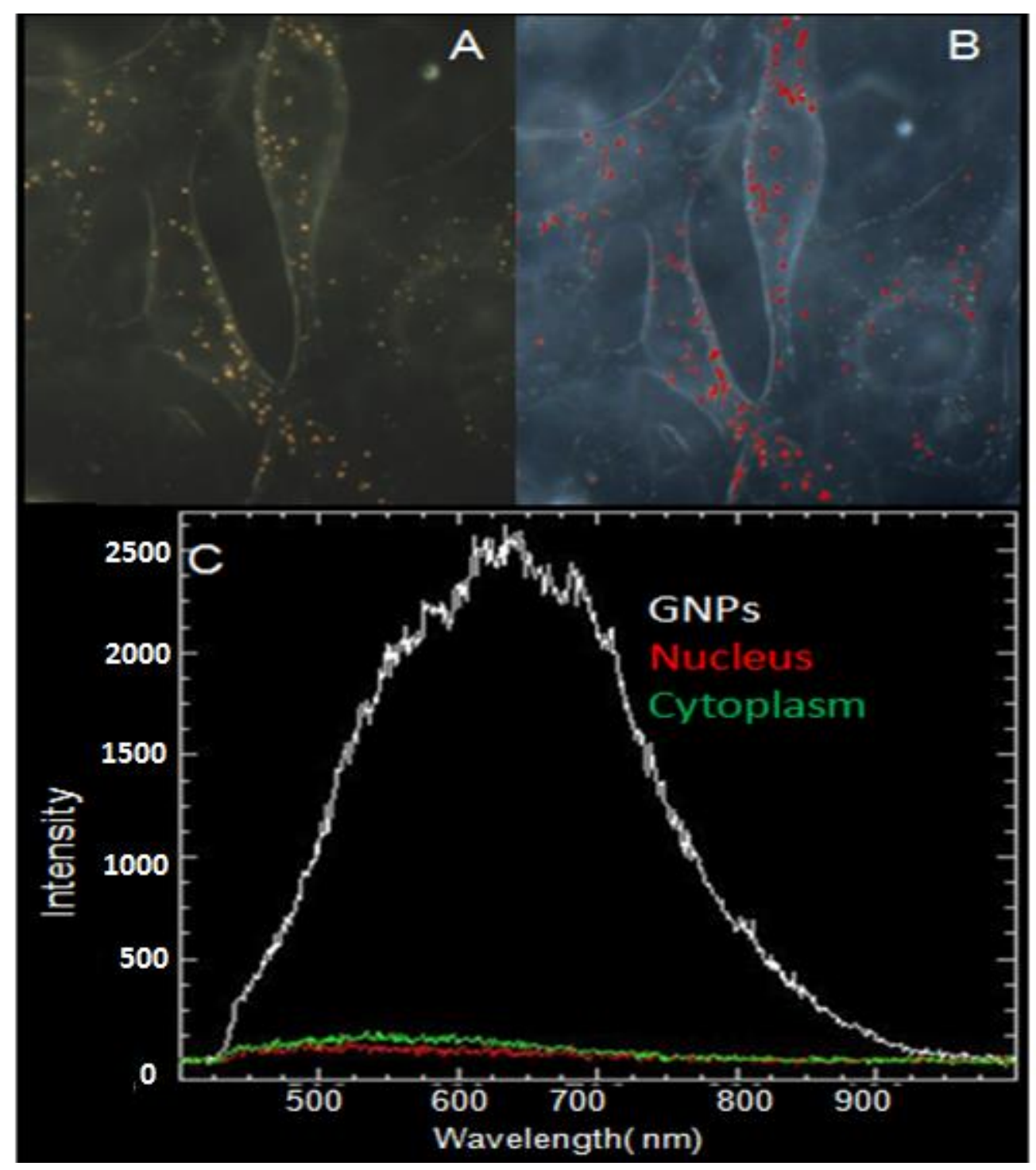

<Fig. 2.3> CytoVivaHyperspectral imaging of GNPs internalized in cells. (A) The darkfield image of GNPs in cells. (B) The spectral angle map overlaid onto the hyperspectral darkfield image. The spectrum from each pixel is compared with reflectance spectra from gold, and if a match is determined, the pixels are coloured red. (C) The reflectance spectra from one of the GNPs (white line) and the background reflectance from the nucleus (red line) and the cytoplasm (green line). 


\subsection{Results and Discussion}

\subsubsection{Characterization of GNP-peptide complexes}

The size of the GNPs used in this study was approximately $15 \mathrm{~nm}$ in diameter. Larger NPs cannot travel through the nuclear pore complex (as discussed in the introduction section). The GNP-peptide complexes used in this study were prepared by assembling the three peptides $\left(\mathrm{P}_{\mathrm{NLS}}, \mathrm{P}_{\mathrm{RGD}}, \mathrm{P}_{\text {Penta }}\right)$ onto the NP surface. NP complexes were characterized using UV visible spectroscopy, DLS, and zeta potential measurements (see Fig. 2.2). The increase in size according to the DLS measurements show that peptides were attached, however, the increase in size was not large enough to hinder the GNPs ability to enter the nucleus (Fig. 2.2 B). This was because the peptides are only few nanometres in size. However, the zeta potential changes from a negative value to a positive one (Fig.2.2 B). The negative charge of the non-conjugated (citrate-capped) GNPs is due to the capping of the citrate molecules. Peptides are positively charged and therefore GNPs were positively charged following conjugation with the peptides. The peptide-GNP complexes were tested for their stability in cell culture media before using them for cell uptake and transport studies. Nanoparticles were further characterised using their reflectance spectra as illustrated in Fig. 2.2 C,D.

\subsubsection{Cell uptake studies using peptide-GNP complex}

Cellular uptake of peptide-GNP complexes was characterized using HeLa cells, a wellknown human fibroblast epithelial cell line. The cellular uptake data proved that the cells targeted with a peptide containing RGD components had the highest NP uptake as compared to cells targeted with citrate-capped NPs (as made GNPs). It is believed that the synthetic peptide $\left(\mathrm{P}_{\mathrm{RGD}}\right)$ with an integrin binding domain (RGD) supplemented an additional driving force for the 
cell entry of NPs. The increase in uptake of NPs functionalized with $\mathrm{P}_{\text {Pent }}$ alone could be due to their positive charge. Positively charged NPs have a higher uptake compared to negatively charged (citrated-capped) $\mathrm{NPs}^{36}$. Cell uptake was lower for NPs conjugated with both $\mathrm{P}_{\mathrm{NLS}}$ and $\mathrm{P}_{\mathrm{RGD}}$ as compared to NPs conjugated with $\mathrm{P}_{\mathrm{RGD}}$ alone. This could be due to the reduction in the number of $\mathrm{P}_{\mathrm{RGD}}$ present on the NP surface. The optimized ratio of peptides used was 1:1 for improving both NP internalization and nuclear localization. The combination of NLS and RGD enable effective cell entry and nuclear localization as illustrated in Fig. 2.4. 


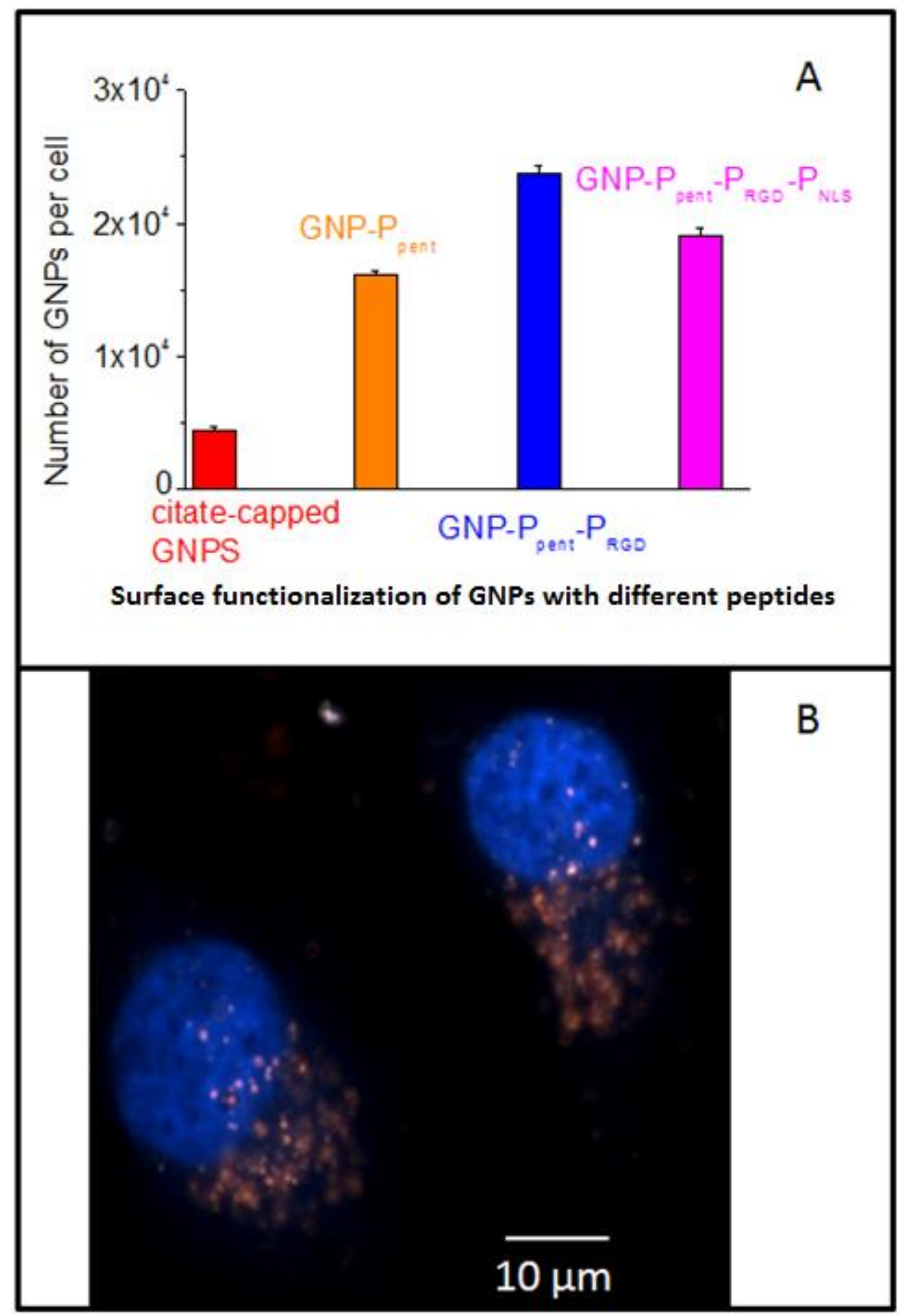

<Fig. 2.4> NP uptake data for peptide conjugated GNPs. (A) Cell uptake data corresponding to the presence of each peptide alone and the combined presence of three peptides on GNPs (Error bars represent standard deviation of $n=3$ ). (B) CytoViva Hyperspectral imaging of cells internalized with GNPs functionalized with pentapeptide, NLS, and RGD peptides. The bright dots represent GNPs. The scale bar represents $10 \mu \mathrm{m}$. 


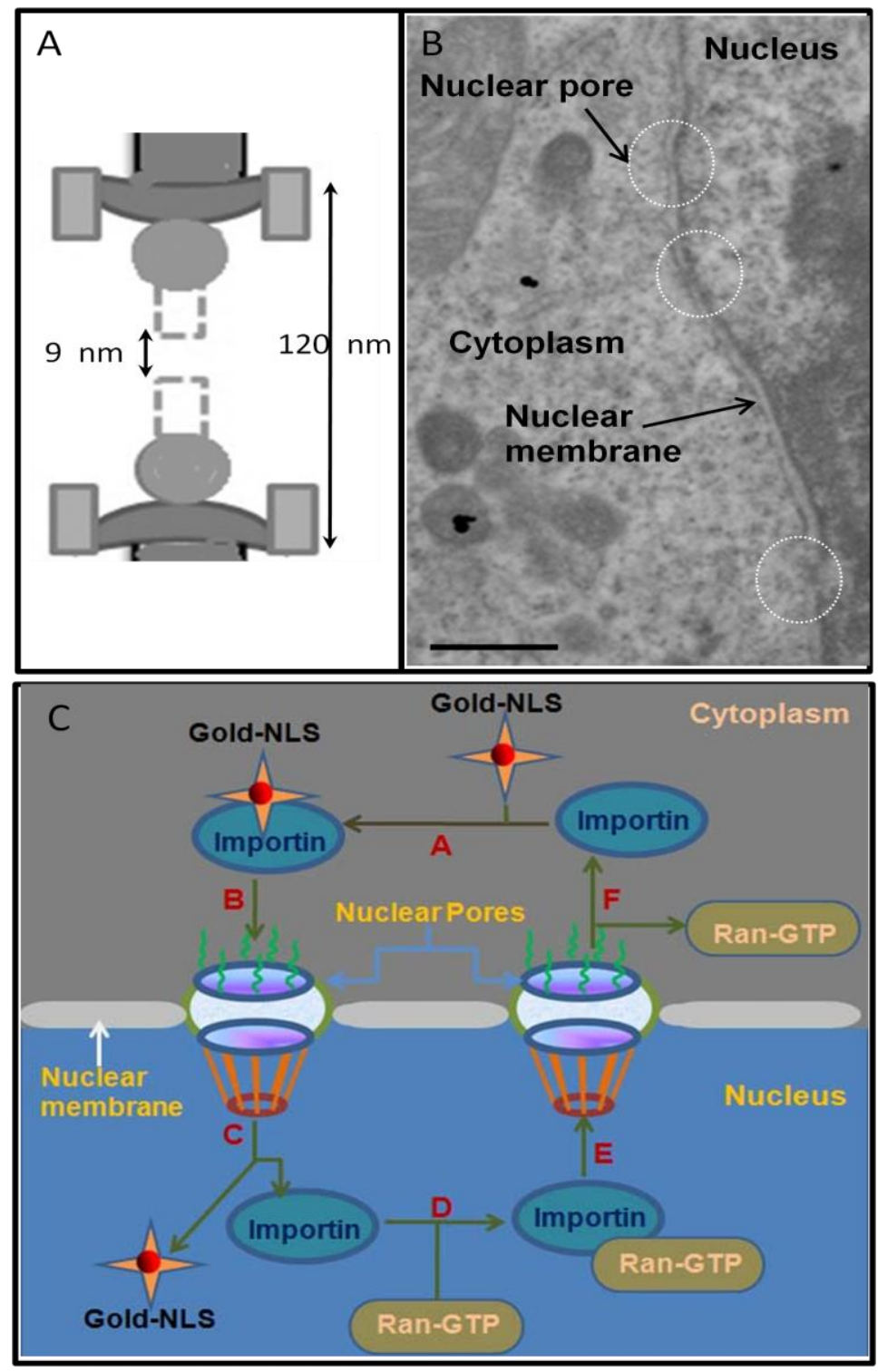

<Fig. 2.5> Mechanism of nuclear transport GNP-peptide complex. (A) Schematic illustrating the cross-section of the nuclear pore complex. (B) TEM image showing few nuclear pores in the nuclear membrane (scale bar $=100 \mathrm{~nm}$ ). (C) Mechanism of selective nuclear transport. GNP-peptide complexes, which possess a Nuclear Localization Signal (NLS), were bound to importin and were transported through the NPC. Mediators, such as the small GTPase Ran, play a vital role in both the GNP-peptide complex release and the recycling of importin into the cytoplasm through NPC. 


\subsubsection{Mechanism of nuclear transport}

One of the features that differentiate a eukaryotic cell from a prokaryotic cell is the presence of a nucleus. The nucleoplasm and the genetic material are separated from the cytoplasm by the nuclear envelope, a double membrane bilayer ${ }^{37}{ }^{38}$. The entry and exit of molecules from the nucleus is mainly through the Nuclear Pore Complex (NPC) (see Fig. 2.5 A, B). Large proteinaceous assemblies, NPCs, are embedded throughout the nuclear membrane that forms selective channels perforating the double membrane surrounding the nucleus ${ }^{37}$. The role of these structures is to serve as sole mediators of nucleocytoplasmic exchange and transport of macromolecules with high specificity ${ }^{37,39}$. NPC is a complex cylindrical structure with octagonal symmetry, $100-150 \mathrm{~nm}$ in diameter, $50-70 \mathrm{~nm}$ in thickness, and 125 million Dalton in mass depending on the organism ${ }^{38}$. The number of NPCs varies from around $3000-4000$ per nucleus, depending on the activity level of a cell ${ }^{40}$. A core structure containing eight spokes surrounding a central tube is present within each $\mathrm{NPC}^{38}$.Peripheral filaments are attached to the core and form a basket-like structure on the nuclear side of the complex ${ }^{38}$.Passive diffusion of ions, water and small proteins of less than $60 \mathrm{kDa}$ occur through longitudinal channels $(10 \mathrm{~nm}$ diameter and 50 $\mathrm{nm}$ in length form) localized between spokes ${ }^{40}$.The transport of larger particles occur through energy dependent active transport via specific receptor proteins ${ }^{40}$. The pore gate is a dynamic structure and opens up to approximately $30 \mathrm{~nm}^{38,40}$. Transport of macromolecules across the NPC require specific amino acid sequence spans, known as Nuclear Localization Sequences $(\mathrm{NLSs})^{38}$. Karyopherins, such as importins, are required to bring cargo to the NPCs ${ }^{38}$. Karyopherins can bind the cargoes directly or via an adaptor protein ${ }^{38,41,42}$.The import substrate binds to the importin in the cytoplasm, which then docks to the cytoplasmic periphery of the NPC. The substrate-importin unit is subsequently translocated to the nuclear side of the NPC, 
mediated by the Ran GDP/GTP cycle ${ }^{41}$. The translocation is terminated on the nuclear side of the NPC which is followed by direct binding of Ran-GTP to importin that causes dissociation between the substrate and the importin ${ }^{41}$. The importin is exported back to the cytoplasm and the cycle continues (see Fig. 2.5 C) ${ }^{38,41}$. Although small molecules (less than $9 \mathrm{~nm}$ in diameter) can enter the nucleus without regulation, larger molecules (greater than $39 \mathrm{~nm}$ in diameter) such as NPs, require association with importin to enter the nucleus via an active transport process. Peptide-GNP complexes, which must be imported to the nucleus from the cytoplasm, should carry NLS for binding to importin as illustrated in Fig. 2.5 C. The importin proteins in the cytoplasm bind to the NLS peptide on the peptide-GNP complexes, after which they are able to interact with the NPC to subsequently pass through its channel. Once NPCs are inside the nucleus, the interaction with Ran-GTP produces a conformational change in the importin, thus causing it to dissociate from its GNP complex. Importin proteins, which act as receptors for nuclear transport, recycle back into the cytoplasm resembling the recycling process of cell membrane receptors. 


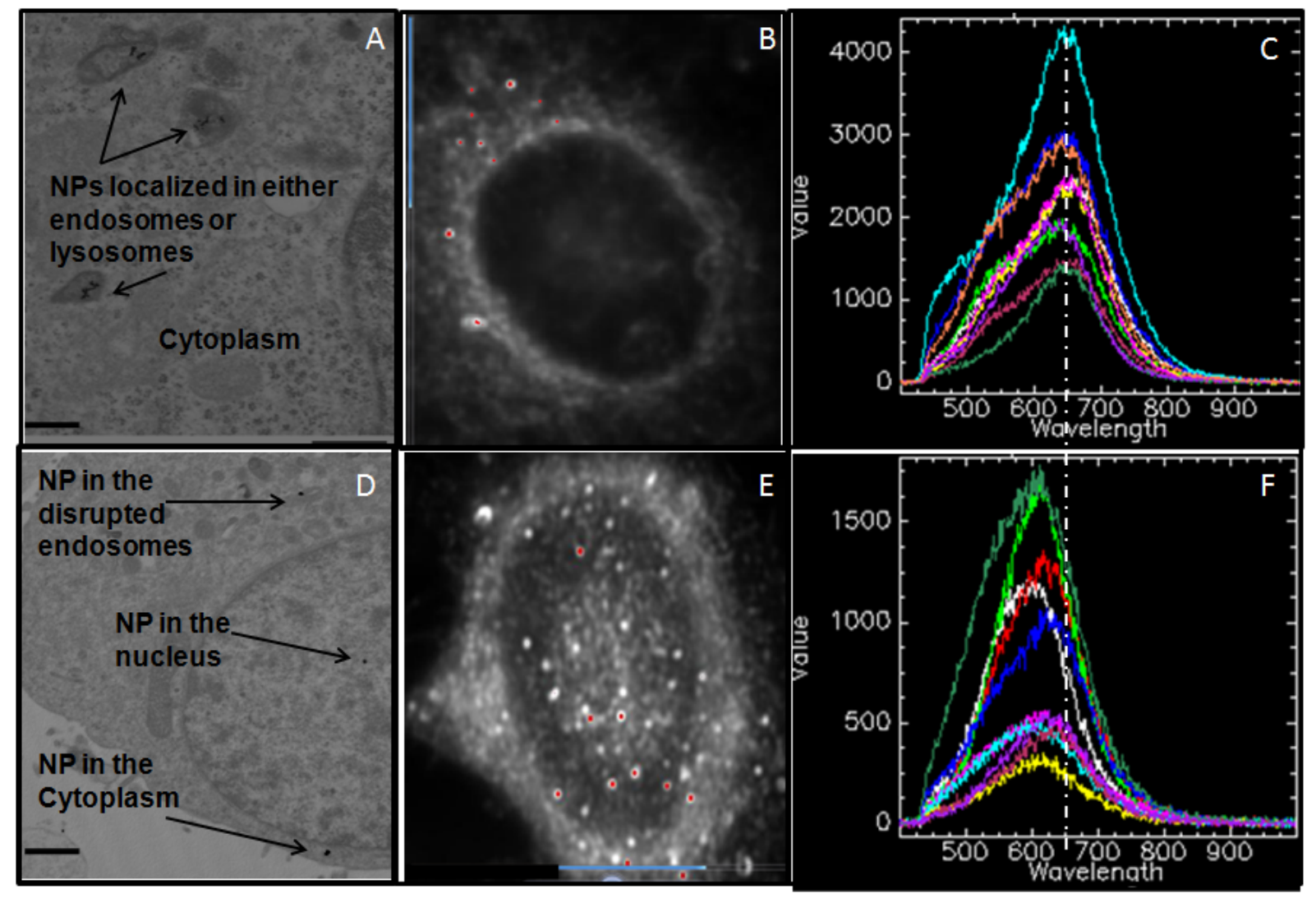

<Fig. 2.6> TEM and Hyperspectral imaging of citrate-capped and peptide-GNPs internalized in cells. (A) TEM image of citrate-capped (non-targeted) GNPs localized in either endosomes or lysosomes. (B) Darkfield image of a cell internalized with non-targeted GNPs. (C) Reflected spectra collected from few GNPs clusters (marked red in image B). (D) TEM image of peptide-capped (nuclear-targeted) GNPs localized in either disrupted endosomes or cytoplasm. (E) Darkfield image of a cell internalized with nuclear-targeted GNPs. (F) Reflected spectra collected from few GNPs clusters (marked red in image E) (scale bar $=100 \mathrm{~nm}$ ).

\subsubsection{Distribution of citrate-capped and peptide-capped GNPs within cells}

We have investigated the variation of NP distribution in cells internalized with citrate-capped and peptide-capped NPs using TEM and hyperspectral imaging. The citrate-capped GNPs travel through the regular endo-lyso path causing NPs to become trapped in either endosomes or lysosomes as clusters in the cytoplasm (Fig. 2.6 A). TEM images confirmed that NPs were not 
localized in the nucleus. Fig. 2.6 B is a darkfield hyperspectral image plane taken across a nucleus of a cell incubated with citrate-capped NPs. Nanoparticles were not localized in the nucleus as expected. Fig. 2.6 C shows that the reflected spectra from few NP clusters peaked around $650 \mathrm{~nm}$. The bottom panel of Fig. 2.6 illustrates the cellular distribution of peptideconjugated NPs. As illustrated in Fig. 2.6 D, most of the NPs were either in disrupted endosomes, cytoplasm, or in the nucleus. Figure 2.6 E is a darkfield hyperspectral image plane taken across a nucleus of a cell incubated with peptide-capped NPs. It clearly demonstrates the localization of NPs within the nucleus. Fig. 2.6 F displays that the reflected spectra from few NPs peaked around $600 \mathrm{~nm}$. This blue shift of the spectra indicates that NPs are not clustered together. However, in the case of citrate-capped ones, NPs were clustered together in the endosomes or lysosomes, as illustrated in TEM images (Fig. 2.6 A, D). Figure 2.7 further illustrates the NP distribution for peptide-conjugated GNPs. The top panel in Fig.2.7 shows TEM images of GNPs localized in the cytoplasm and nucleus. The bottom panel displays the three dimensional (3D) distribution of NPs within a cell. Figure 2.7 D is a darkfield image of a cell chosen for 3D mapping of the NP distribution. The white dots represent NPs localized in a particular image panel. A stack of imaging planes was acquired in the $\mathrm{Z}$ direction to cover the full height of the cells. All stacks were acquired with the CytoViva 3-D acquisition software. The stacks were deconvolved and the GNPs were identified using the CytoViva 3-D Analysis Software. Figure 2.7 E displays the 3D distribution of GNPs within the cell shown in Fig. 2.7 D. The red dots represent GNPs. The nucleus (marked in a blue colour) was introduced in the Fig. 2.7 $\mathbf{F}$ to show that NPs were inside the nucleus as well. This is a novel imaging technique that can be used to image GNPs without using any optical probes. This is the first time that such a 3D distribution of nuclear targeted NPs was obtained. 

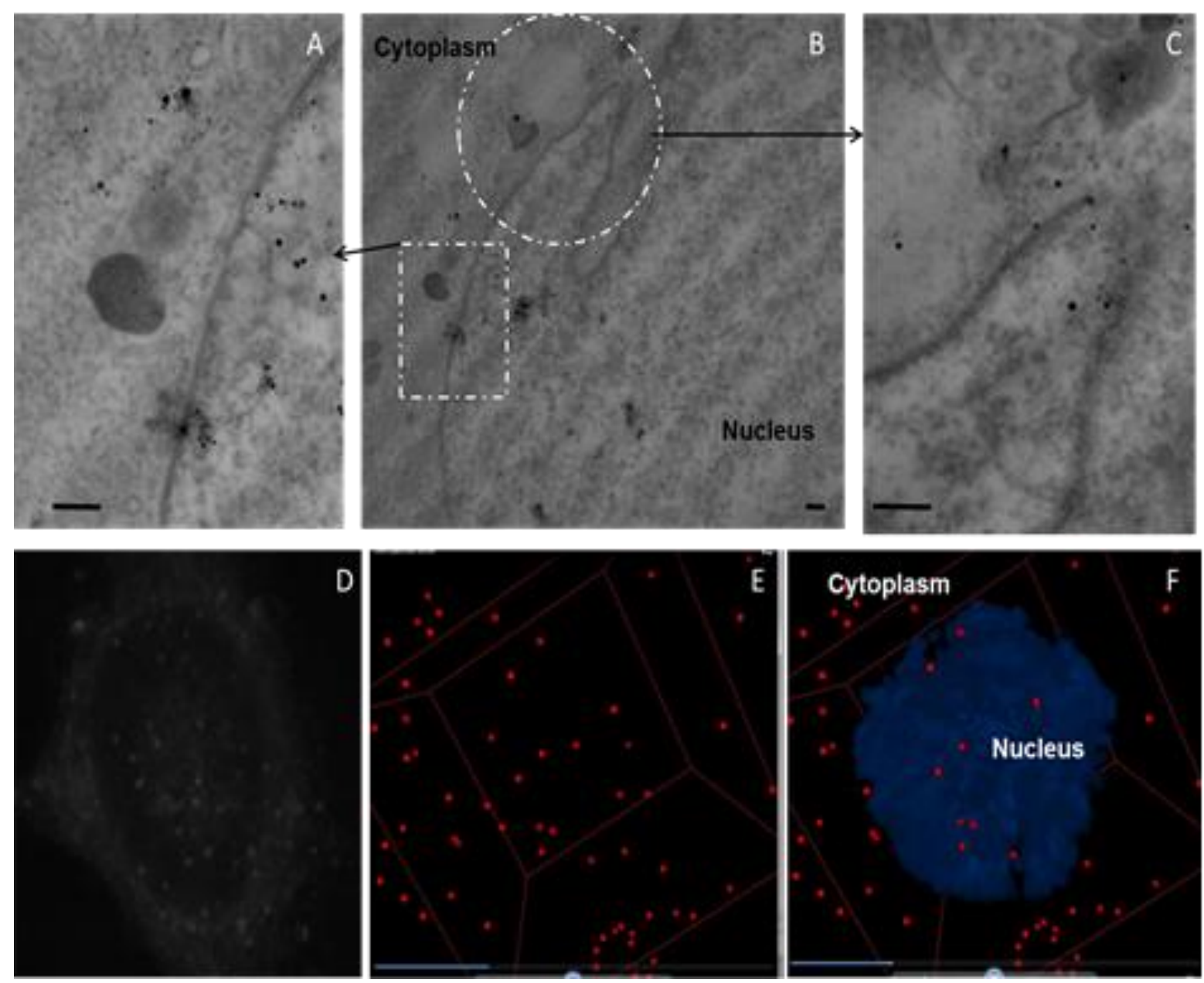

< Fig. 2.7> 2D and 3D view of localization of peptide-capped GNPs within the cell. (A-C) Two dimensional (2D) view of localization of peptide-modified GNPs in the cytoplasm and nucleus using TEM imaging. (A) and (C) are insets of (B). (D-F) Hyperspectral imaging of a cell targeted with peptide-conjugated GNPs. (D) Darkfield image of the cell used for three dimensional (3D) rendering. (E) 3D view of the NPs localized in the cells. Red dots represent GNPs. (F) Nucleus (blue in colour) is added to show the co-localization (Scale bar $=100 \mathrm{~nm}$ ). 


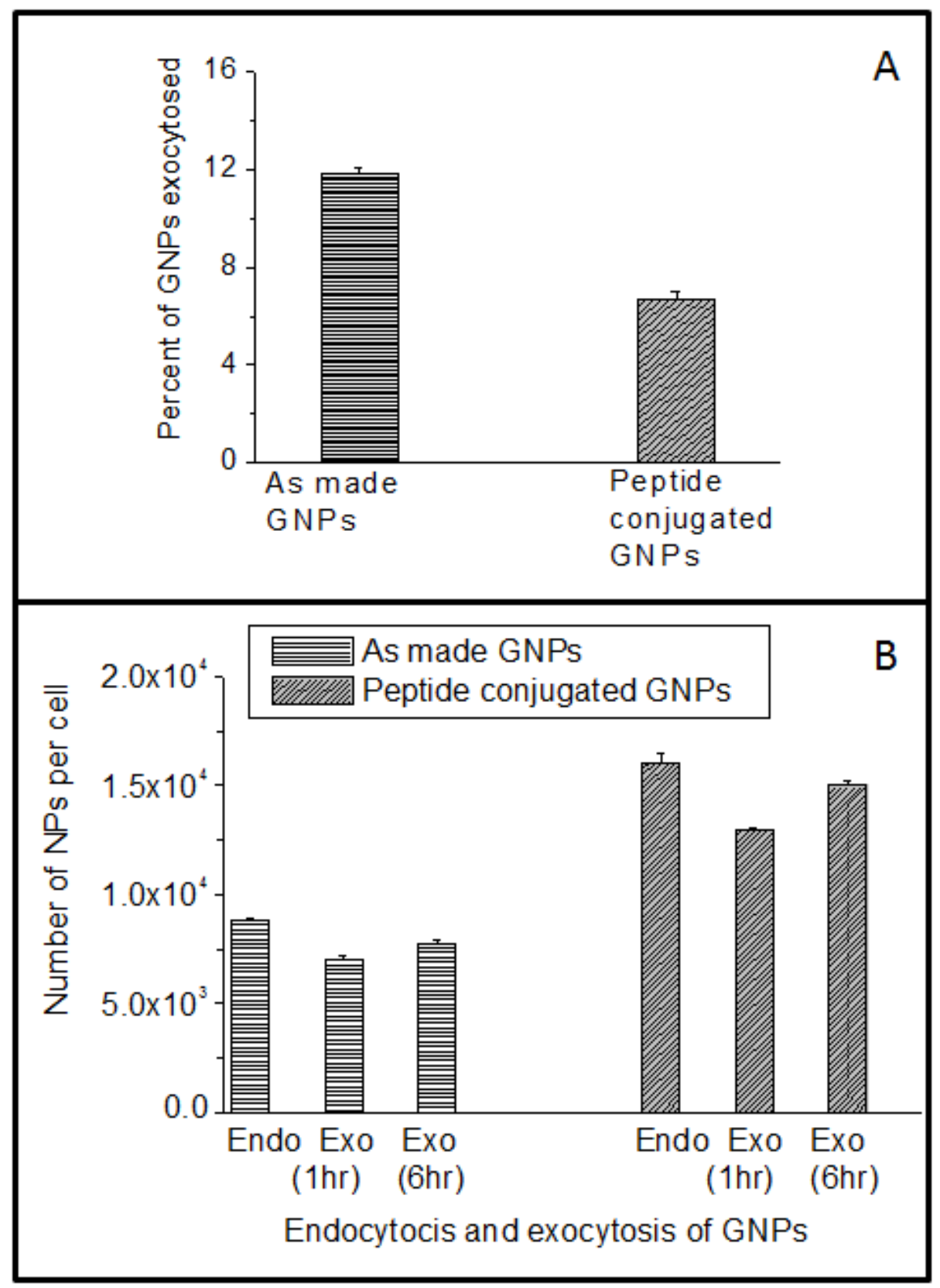

<Fig. 2.8> Exocytosis of peptide-capped GNPs. (A) Percent of NPs exocytosed for cells incubated with citrate-capped and peptide-capped GNPs. (B) Dynamics of exocytosis process following one and six hours (Error bars represent standard deviation of $n=3$ ). 


\subsubsection{Exocytosis of peptide-conjugated GNPs}

Previous work has shown that the exocytosis process depends on the cell type, NP size, and surface properties of $\mathrm{NPs}^{15,43}$. Hence, the assessment of exocytosis has to be performed for every specific condition. The exocytosis of GNPs functionalized with nuclear targeting peptides is not properly known yet. Our studies have shown, for the first time, that the fraction of NPs exocytosed was lower by two-fold for cells targeted with peptide-conjugated NPs (Fig. 2.8A). Citrate-capped NPs were localized in endosomes followed by processing via fusion with lysosomes. NPs localized in lysosomes are excreted into the extracellular matrix by fusing with the cell membrane. However, most of the GNPs capped with peptides were able to enter the cytoplasm to reach the nucleus. This increase in the residence time in the cytoplasm and nucleus could lead to slower exocytosis process (see <Fig 2.8>). Our results are in agreement with previously published work for CuO NPs and silica NPs. For example, Wang et al. evaluated the excretion of $\mathrm{CuO}$ NPs in A549 cells and discovered that a portion of NPs, which were located in mitochondria and nucleus, could not be excreted by the cells ${ }^{44}$. Similarly, based on findings by Chu et al., clusters of silica NPs in lysosomes are more easily exocytosed by H1299 cells compared to single NPs in the cytoplasm ${ }^{45}$. We evaluated the exocytosis process as a function of time. As illustrated in Fig. 2.8 B, a significant portion of the NPs were able to re-enter the cells. The percent of NPs re-entering the cells was $10 \%$ and $15 \%$ respectively, for citrate-capped (nontargeted) and peptide-capped (nuclear targeted) NPs. Nuclear targeted NPs seem to aggregate less within the cell (see Fig. 2.6). Hence, it is possible for these NPs to re-enter cells once excreted. This could be one of the reasons for an increase in NPs present in cells targeted with peptides following a prolonged exocytosis process. The enhanced retention of NPs within cells 
can be used for improved therapeutics in radiation therapy and chemotherapy as discussed in the introduction section.

\subsection{Conclusions}

Our results showed that the fuctionalization of GNPs with RGD peptide enhanced the NP uptake by five-fold. The combination of RGD peptide and NLS peptide allowed efficient nuclear targeting. Our studies showed that the fraction of NPs exocytosed was lower by a factor of two for cells targeted with peptide-conjugated NPs in comparison to citrate-capped (non-targeted) NPs. This prolonged intracellular retention of peptide functionalized NPs could allow NPs to exert their desired applications more efficiently in cells, especially in drug delivery. Hence, a proper understanding of endocytosis and exocytosis dynamics will shed more light on the design of GNPs in demand for cancer therapeutic applications.

\subsection{Acknowledgements}

The authors would like acknowledge Natural Sciences and Engineering Research Council of Canada (NSERC), Canadian Foundation of Innovation (CFI) and Ryerson University for their financial support.

\subsection{Notes and References}

${ }^{a}$ Department of Physics, Ryerson University, 350 Victoria Street, Toronto, ON, Canada, M5B 2K3,

${ }^{b}$ CytoVivalnc, 570 Devall Drive, Auburn, AL, USA, 36832.

1. Cuenca, A. G.; Jiang, H.; Hochwald, S. N.; Delano, M.; Cance, W. G.; Grobmyer, S. R., Emerging implications of nanotechnology on cancer diagnostics and therapeutics. Cancer 2006, 107, 459-466.

2. Rao, j., Shedding Light on Tumors Using Nanoparticles. ACS Nano 2008, 2, 1984-1986. 
3. Chithrani, B. D., Optimization of Bio-Nano Interface Using Gold Nanostructures as a Model Nanoparticle System. Insciences J 2011, 1, 136-156.

4. Jelveh, S.; Chithrani, D. B., Gold Nanostructures as a Platform for Combinational Therapy in Future Cancer Therapeutics. Cancers 2011, 3, 1081-1110.

5. Hauck, T. S.; Jennings, J. L.; Yatsenko, T.; Kumaradas, J. C.; Chan, W. C. W., Enhancing the Toxicity of Cancer Chemotherapeutics with Gold Nanorod Hyperthermia. Adv Mater 2008, 20, 3832-3838.

6. Alivisatos, P., The use of nanocrystals in biological detection. Nat. Biotech. 2003, 22, 47-51.

7. Liong, M.; Lu, J.; Kovochich, M.; Xia, T.; Ruehm, S. G.; Nel, A. E.; Tamanoi, F.; Zink, J. I., Multifunctional Inorganic Nanoparticles for Imaging, Targeting, and Drug Delivery. ACS Nano 2008, 2, 889-896.

8. Langereis, S.; Keupp, J.; van Velthoven, J. L. J.; de Roos, I. H. C.; Burdinski, D.; Pikkemaat, J. A.; Grüll, H., A Temperature-Sensitive Liposomal 1H CEST and 19F Contrast Agent for MR Image-Guided Drug Delivery. J. Am. Chem. Soc. 2009, 9, 1380-1381.

9. Perrault, S. D.; Walkey, C.; Jennings, T.; Fischer, H. C.; Chan, W. C. W., Mediating Tumor Targeting Efficiency of Nanoparticles Through Design. Nano Lett. 2009, 9, 1909-1915.

10. Lee, J. E.; Lee, N.; Kim, H.; Kim, J.; Choi, S. H.; Kim, J. H.; Kim, T.; Song, I. C.; Park, S. P.; Moon, W. K.; Hyeon, T., Uniform Mesoporous Dye-Doped Silica Nanocrystals for Simultaneous Enhanced Magnetic Resonance Imaging, Fluorescence Imaging, and Drug Delivery. J. Am. Chem. Soc. 2010, 132, 552-557.

11. Chithrani, B. D., Intracellular uptake, transport, and processing of gold nanostructures. Mol Membr Biol 2010, 27, 299-311.

12. Bergen, J. M.; van Recum, H. A.; Goodman, T. T.; Massey, A. P.; Pun, S. H., Gold Nanoparticles as a Versatile Platform for Optimizing Physicochemical Parameters for Targeted Drug Delivery. Macromol Biosci 2006, 6, 506-516.

13. Shukla, R.; Bansal, V.; Chaudhary, M.; Basu, A.; Bhonde, R. R.; Sastry, M., Biocompatibility of Gold Nanoparticles and Their Endocytotic Fate Inside the Cellular Compartment: A Microscopic Overview. Langmuir 2005, 21, 10644-10654.

14. Chithrani, B. D.; Ghazani, A. A.; Chan, W. C. W., Determining the Size and Shape Dependence of Gold Nanoparticle Uptake into Mammalian Cells. Nano Lett 2006, 6, 662-668.

15. Chithrani, B. D.; Chan, W. C. W., Elucidating the Mechanism of Cellular Uptake and Removal of Protein-Coated Gold Nanoparticles of Different Sizes and Shapes. Nano Lett 2007, 7, 1542-1550.

16. Xu, X.-H. N.; Brownlow, W. J.; Kyriacou, S. V.; Wan, Q.; Viola, J. J., Real-Time Probing of Membrane Transport in Living Microbial Cells Using Single Nanoparticle Optics and Living Cell Imaging. Biochem 2004, 43, 10400-10413. 
17. Gao, H.; Shi, W.; Freund, L. B., Mechanics of receptor-mediated endocytosis. . Proc Natl Acad Sci USA 2005, 102, 9469-9474.

18. Shi, W., Wang J, Fan X, Gao H, Size and shape effects on diffusion and absorption of colloidal particles near a partially absorbing sphere: Implications for uptake of nanoparticles in animal cells. Phy Rev E 2008, 78, 061914-061925.

19. Zhang, S.; Li, J.; Lykotrafitis, G.; Bao, G.; Suresh, S., Size-dependent Endocytosis of Nanoparticles. Adv Mater 2009, 21, 419-424.

20. Yang, C.; Neshatian, M.; Van Prooijen, M.; Chithrani, B. D., Cancer Nanotechnology: Enhanced Therapeutic Response Using Peptide-Modified Gold Nanoparticles. J Nanosci Nanotechnol. 2014, 14, 4813-4819

21. Tkachenko, A. G., Xie H, Coleman D, Glomm W, Ryan J, Anderson M F, Franzen S, Feldheim DL., Multifunctional Gold Nanoparticle-Peptide Complexes for Nuclear Targeting. J Am Chem Soc 2003, 125, 4700-4701.

22. Souza, G. R.; Christianson, D. R.; Staquicini, F. I.; Ozawa, M. G.; Snyder, E. Y.; Sidman, R. L.; Miller, J. H.; Arap, W.; Pasqualini, R., Networks of gold nanoparticles and bacteriophage as biological sensors and cell-targeting agents. . Proc Natl Acad Sci USA 2006, 103, 1215-1220.

23. Berry, C. C.; de la Fuente J.M; Mullin, M.; Chu, S. W. L.; Curtis, A. S. G., Nuclear Localization of HIV-1 Tat Functionalized Gold Nanoparticles. IEEE Trans NanoBiosci 2007, 6, 262-269.

24. Oyelere, A. K.; Chen, P. C.; Huang, X.; El-Sayed, I. H.; El-Sayed, M. A., Peptide-Conjugated Gold Nanorods for Nuclear Targeting. Bioconjug Chem 2007, 18, 1490 - 1497.

25. Nativo, P.; Prior, I. A.; Brust, M., Uptake and Intracellular Fate of Surface-Modified Gold Nanoparticles ACS Nano 2008, 2, 1639-1644.

26. Bartczak, D.; Nitti, S.; Millarb, T. M.; Kanaras, A. G., Exocytosis of peptide functionalized gold nanoparticles in endothelial cells. Nanoscale 2012, 4, 4470-4472.

27. De la Fuente, J. M.; Berry, C. C., Tat Peptide as an Efficient Molecule to Translocate Gold Nanoparticles into the Cell Nucleus. Bioconjugate Chem 2005, 16, 1176-1180.

28. Tkachenko AG, X. H., Liu Y, Coleman D, Ryan J, Glomm WR, Shipton MK, Franzen S, Feldheim DL., Cellular Trajectories of peptied-Modified Gold Particle Complexes: Comparison of Nuclear Localization Signals and Peptide Transduction Domains. Bioconjug chem 2004, 15, 482-490.

29. Kang, B.; Mackey, M. K.; El-Sayed, M. A., Nuclear Targeting of Gold Nanoparticles in Cancer Cells Induces DNA Damage, Causing Cytokinesis Arrest and Apoptosis. J Am Chem Soc 2010, 132, 1517-1519. 
30. Ryan, J. A.; Overton, K. W.; Speight, M. E.; Oldenburg, C. N.; Loo, L.-N.; Robarge, W.; Franzen, S.; Feldheim, D. L., Celluar Uptake of Gold Nanoparticles Passivated with BSA-SV40 Large T Antigen Conjugates. Anal chem 2009, 79, 9150-9159.

31. Hart, S., Harbottle, R., and Coutelle, C. (Gregoriadis, G., and McCormack, B., Eds.) IntegrinMediated Gene Delivery, in Targeting of Drugs 5: Strategies for Oligonucleotide and Gene Delivery in Therapy. Plenum Press, New York, London.

1995, 101-106.

32. Frens, G., Controlled nucleation for the particle size in monodisperse gold suspensions. Nature 1973, 241, 20-22.

33. Hermanson, G. T., Preparation of colloidal-gold-labeled proteins, in Bioconjugate techniques. Academic press, Newy York, USA

1996, 593-605.

34. Kah, J. C. Y.; Kho, K. W.; Lee, C. G. L.; Sheppard, C. J. R.; Shen, Z. X.; Soo, K. C.; Olivo, M. C., Early diagnosis of oral cancer based on the surface plasmon resonance of gold nanoparticles. Int J Namomed 2007, 2, 785-798.

35. Viator, J. A.; Gupta, S.; Goldschmidt, B. S.; Bhattacharyyal, K.; Kannan, R.; Shukla, R.; Dale, P. S.; Boote, E.; Katti, K., Gold nanoparticle mediated detection of prostate cancer cells using photoacoustic flowmetry with optical reflectance. J Biomed Nanotechnol. 2010, 6, 187-191.

36. Frohlich, E., The role of surface charge in cellular uptake and cytotoxicity of medical nanoparticles. Int J Namomed 2012, 7, 5577-5591.

37. Fernandez-Martinez, J.; Rout, M. P., Nuclear pore complex biogenesis. Curr Opin Cell Biol 2009, $21,603-612$.

38. Wente, S. R.; Rout, M. P., The nuclear pore complex and nuclear transport. Cold Spring Harb perspect biol 2010, 2, a000562-a000562.

39. Suntharalingam, M.; Wente, S. R., Peering through the pore: Nuclear pore complex structure, assembly, and function. Developmental cell 2003, 4, 775-789.

40. Pavelka, M.; Roth, J., Nuclear pore complexes. Functional Untrastructure 2010, Springer Vienna, 16-17.

41. Görlich, D., Nuclear protein import. CurrOpin Cell Biol 1997, 9, 412-419.

42. Pemberton, L. F.; Paschal, B. M., Mechanisms of receptor-mediated nuclear import and nuclear export. Traffic 2005, 6, 187-198. 
43. Bartczak, D.; Sanchez-Elsner, T.; Louafi, F.; Millar, T. M.; Kanaras, A. G., Receptor-mediated interactions between colloidal gold nanoparticles and human umbilical vein endothelial cells. Small 2011, 7, 388-394.

44. Wang, Z.; Li, N.; Zhao, J.; White, J. C.; Qu, P.; Xing, B., CuO nanoparticle interaction with human epithelial cells: cellular uptake, location, export, and genotoxicity. Chem Res Toxicol 2012, 25, 15121521.

45. Chu, Z.; Huang, Y.; Tao, Q.; Li, Q., Cellular uptake evolution, and excretion of silica nanoparticles in human cells. Nanoscale 2011, 3, 3291-3299. 


\section{Summary and Future work}

\subsection{Summary}

The purpose of this project was to conjugate GNPs with peptides for nuclear targeting and to determine whether cells incubated with peptide-conjugated GNPs have an improvement in radiation treatment compared to cells incubated with naked GNPs and the control cells.

In this study, three different peptides were conjugated onto the surface of $15 \mathrm{~nm}$ GNPs where the roles of each of the peptides were to increase uptake and cellular retention, to signal for nuclear uptake, and to stabilize the whole complex. The targeted GNPs and untargeted GNPs were added to the confluent dish of Hela cells for an incubation 8 hour period. Both samples were visualized under the CytoViva microscope with the attached DAGE and HSI camera. A beta version of CytoViva's 3-dimentional reconstruction software was used to observe part of the targeted GNPs inside the nucleus whereas the untargeted GNPs remained in the cytoplasm of the cell.

Inductively Coupled Plasma-Atomic Emission Spectroscopy (ICP-AES) was used to measure the amount of GNPs inside the cells. Cells incubated with peptide-conjugated GNPs had an approximately 3 fold increase in the amount of GNP per cell compared to the cells incubated with untargeted GNPs. This shows that the peptides increased uptake and intracellular retention of the GNPs. 


\subsection{In vitro future work: radio therapy}

\section{Introduction}

Delivering the dose that eradicates tumor tissue while not disrupting surrounding healthy tissues has been a challenge and it is still being studied to a great extend to reach the optimal and delicate balance. Many research groups are still searching to improve the current radiation based therapeutic techniques. GNPs are radiation dose enhancers and the dose enhancement is attributed to the production of secondary electrons scattering from the surface of the high- $\mathrm{Z}$ material $^{1,2}$ and this has been confirmed by direct dose measurements ${ }^{3,4}$ and Monte Carlo modeling ${ }^{5,6}$. The increase in the number of secondary electrons attributed to the increase in free radicals that lead to increase in DNA damage upon irradiation and therefore increase in cell death $^{7}$.

The extent of sensitization with GNPs depends on several factors including the beam energy. Greater radiation sensitization was seen for cells irradiated with lower energy beams ${ }^{7,8}$. A Monte Carlo study has been done to verify such findings. As the photoelectric cross-section strongly depends on the energy, irradiating GNPs with a low-energy photon beam would greatly increase the number of secondary electrons compared to GNPs irradiated with high energy beams.

High atomic number materials other than GNPs that were used in the past include iodine, bulk metallic gold and micro diameter sized gold particles. Santos Mello et al. demonstrated that injecting iodine into the tumor suppressed re-growth rate of $80 \%$ after radiation ${ }^{9}$. Nath et al. found introducing iodine into the DNA of the cell through iododeoxyuridine in vitro increased radio-sensitivity by a factor of three ${ }^{10}$. Iodinated compounds, however, can be cleared by the kidney rapidly and sometimes cause renal toxicity ${ }^{11-13}$. Regulla et al. developed a method to 
locally enhance radiation therapy by introducing a metal surface at the site of irradiation (US Patent $6,001,054)^{14}$. The solid metal surface, such as a metallic stent, was placed in the blood vessel adjacent to the tissue to be ablated. One of the drawbacks of this method was that placing bulk metal surfaces throughout all tumor vessels and tissues was impractical. Moreover, the radiation was restricted to less than $400 \mathrm{keV}$, which could not treat tumors at depth ${ }^{7}$. Skin cancers can be treated using this low photon energy range, but such tumors can be removed easily through surgery ${ }^{7}$.

Herold et al. found a dose enhancement of a factor of 1.54 from a clonogenic assay when $1.5-3 \mu \mathrm{m}$ diameter gold particles were added in a stirred suspension prior to irradiating with $100-240 \mathrm{kVp} \mathrm{x}$-rays. This group also injected the same sized gold particles directly into tumor sites. Although reduction in tumor size did not occur, the plating efficiency of the extracted cells was lower than the control cells, 0.15 and 0.25 respectively. Histological data showed that the gold particles were mostly in the interstitial fluid while no particles were found in the tightly packed regions of tumor cells ${ }^{15}$. This implies the particles were non-uniformly dispersed as the larger sized particles are unable to pass through the tightly packed regions. Consequently, NPs in the size range 2-100 $\mathrm{nm}$ were used to deliver therapeutic systems into tumor tissues ${ }^{7,8,16}$. Our recent studies show that GNP uptake and their dose enhancement effects were dependent on the size of the $\mathrm{NP}^{7,17,18}$. However, in many of these studies, the GNPs were localized in the cytoplasm of the cell, therefore causing a less cell kill. In this study, we have targeted the GNPs into the nucleus, in order to investigate the enhancement in therapeutic response in radiotherapy.

Gold having a higher $\mathrm{Z}$ number than iodine can increase the absorption of radiation energy even more that iodine, while it is also biocompatible ${ }^{9,19-23}$ and can access the tumor cells as they are smaller than the typical cutoff size of pores in tumor vasculature ${ }^{24}$. GNPs may be also 
be synthesized to a size that is suitable for efficient cancer cell uptake and even nuclear targeting. The next section shows therapeutic improvement of cells incubated with nuclear targeted GNPs compared to the control cells and the cells incubated with non-targeted GNPs.

\section{Preliminary radiation experiments with nuclear targeted GNPs}

\section{Methodology}

\subsubsection{Synthesis of GNPs}

GNPs of size $14 \mathrm{~nm}$ were synthesized using the citrate reduction method and $300 \mathrm{ml}$ of $1 \%$ $\mathrm{HAuCl} 4.3 \mathrm{H} 2 \mathrm{O}$ was added to $30 \mathrm{ml}$ of double-distilled water followed by heating on a hot plate while stirring. Once it reached the boiling point, $600 \mu 1$ of $1 \%$ anhydrous citric acid) was added to form NPs $14 \mathrm{~nm}$ in diameter. After the color of the solution changed from dark blue to red, the solution was left to boil for another 5 min while stirring. Finally, the GNP solution was brought to room temperature while stirring.

\subsubsection{Peptide conjugation of GNPs}

Peptide-GNP complexes were assembled by first conjugating the GNPs with H-Cys-AlaLeu-Asn-Asn-OH ( $\left.\mathrm{P}_{\text {Pent }}\right)$ with approximately 300 peptides/GNP ratio for stabilization purposes. Following this, the peptide ( $\mathrm{P}_{\text {RGD-NLS }}$ ) with H-Cys-Lys-Lys-Lys-Lys-Lys-Lys-Gly-Gly-Arg-GlyAsp-Met-Phe-Gly-OH sequence was added with an 8 to 10 peptide/GNP ratio. For nuclear targeted GNPs, $\mathrm{P}_{\mathrm{RGD}}$ and $\mathrm{P}_{\mathrm{NLS}}$ peptides (H-Cys-Gly-Gly-Arg-Lys-Lys-Arg-Arg-Gln-Arg-ArgArg-Ala-Pro-OH) were added in a 1:1 ratio. 


\subsubsection{Cell Culture and Particle Delivery}

HeLa (cervical cancer cell line) cells were cultured in Dulbecco's Modified Eagle's Medium (DMEM) supplemented with 10\% Fetal Bovine Serum (FBS). Once 70\% confluent, the cells were incubated with GNPs for 16 hours.

\subsubsection{Irradiation experiment}

HeLa cells were seeded into $35 \mathrm{~mm}$ tissue culture dishes. Once the cells adhered, untargeted GNPs were introduced into one set of dishes, targeted GNPs were introduced to another set, and one set of dishes were lefts as reference cells. After a 16 hour incubation period, the cells were irradiated with $2 \mathrm{~Gy}$ of $220 \mathrm{kVp} \mathrm{X}$ rays. After irradiation, cells were removed for a clonogenic assay.

\subsubsection{Clonogenic Assay}

HeLa cells were grown in DMEM medium at $37^{\circ} \mathrm{C}$ in a humidified incubator with $95 \%$ air $/ 5 \%$ $\mathrm{CO}_{2}$. The cells were first seeded at 100 cells in six tissue culture dishes (35 $\mathrm{mm}$ in diameter) (three for non-irradiated case (one with untargeted GNPs, one with targeted GNPs one without GNPs); three for irradiated case (one with untargeted GNPs, one with targeted GNPs one without GNPs)) and incubated for $24 \mathrm{~h}$. To investigate the dependence of nanoparticle localization on radiation response, GNPs were added to relevant Petri dishes (concentration 7x109 nanoparticles/ml). The cells were then incubated for $3 \mathrm{~h}$ before irradiation and were kept on ice as soon as they were removed from the incubator for irradiation. After irradiation, the cells were trypsinized, and different dilutions were made from the cells incubated with and without GNPs 
to produce an expected (based on preliminary studies) average of 50 colonies in $10 \mathrm{~cm}$ dishes after a dose of $2 \mathrm{~Gy}$. The cells were incubated for 2 weeks to form colonies. Methylene blue $(0.1 \%)$ was used for staining the colonies. The colonies containing $>50$ cells were counted for calculating the surviving fractions. The plating efficiency of the cells was determined by counting the number of colonies at $0 \mathrm{~Gy}$. 


\section{Preliminary results and discussion}

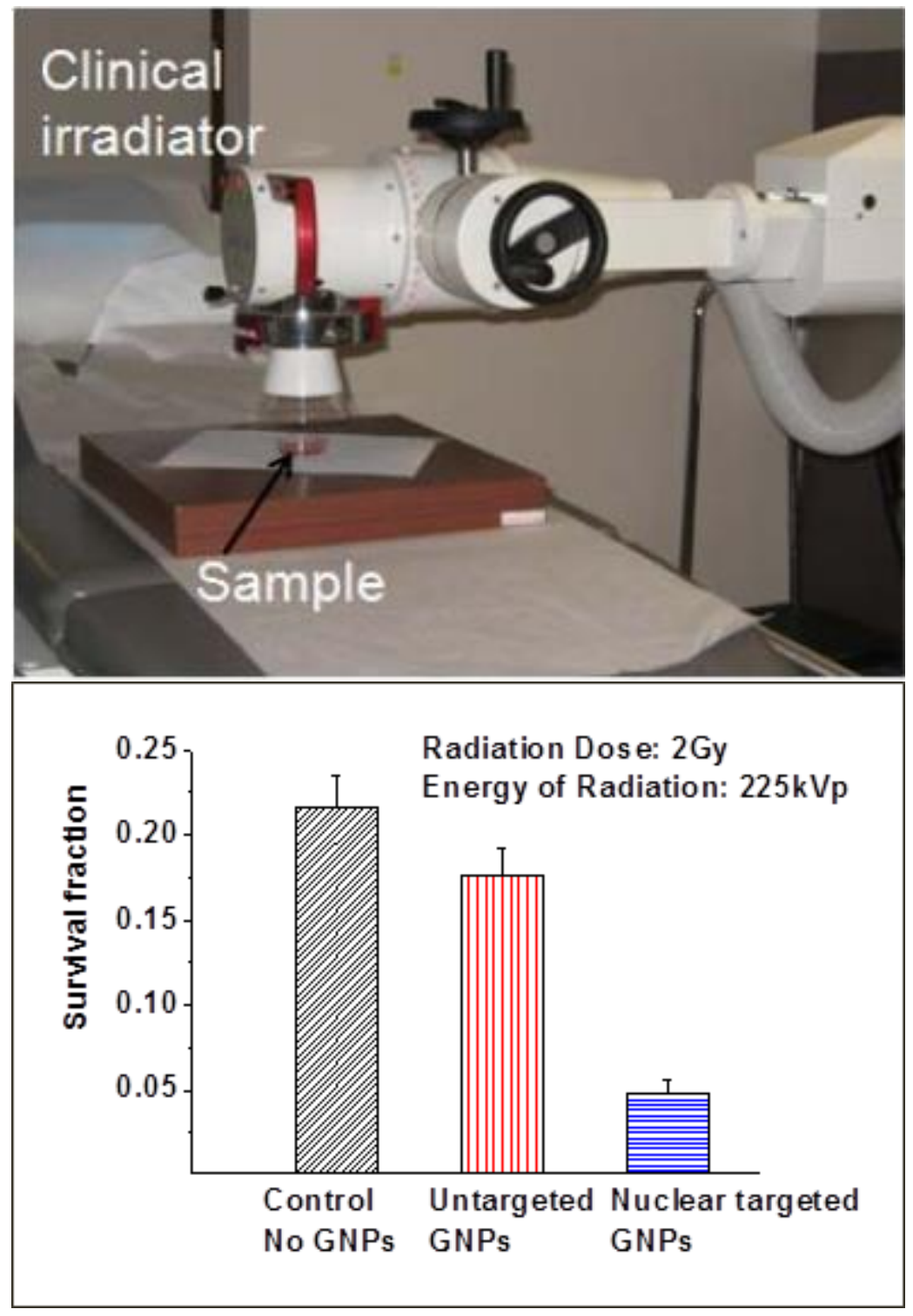

<Fig. 3.1> Improved therapeutics using GNP-peptide complexes. (Top) A clinical machine used to irradiate samples (Bottom) Improved therapeutics (enhanced cell death) of nuclear targeted cells (Error bars represent standard deviation of $n=3$, statistical significance for nuclear targeted cells compared to untargeted and reference cells, $\mathrm{p}<0.05)$. 
These studies support the hypothesis that optimizing the distribution of GNPs within the cell could lead to improved therapeutic response. With nuclear targeting, there is a possibility in the enhancement in the production of radicals, ions and free electrons lowering the survival of cancer cells. The outcome of this research will enable the optimization of GNP-based systems for use in cancer radiotherapy. It has also been demonstrated recently, that the addition of GNPs to anticancer drugs such as cisplatin and other platinum agents enhanced the cell damage. The details will be introduced in the next section.

\subsection{In vitro future work: drug therapy}

\section{Introduction}

The side effects caused by antitumor drugs remain as one of the important problems to overcome in cancer treatment ${ }^{25-27}$. This is mainly induced by poor distribution of the antitumor agents and can be minimized by improving bioavailability of the drug in the tumor region as well

as confining them to the target region ${ }^{27-30}$. The use of nanoparticles as drug carriers has been extensively documented in the last few decades and the advantages of nanoparticle-based drug delivery systems have been recognized by several previous studies ${ }^{27,31-36}$. The solubility of poor water-soluble drugs can be improved, the half-life of drug systemic circulation could be prolonged by reducing immunogenicity, drugs could be target delivered which can minimize systemic side effects, and two or more drugs can be delivered simultaneously for combinational therapy ${ }^{37}$. Combinational therapy can create a synergistic effect and suppress drug resistance. Some nanoparticle-based therapeutic systems have already been introduced into the pharmaceutical market, and many other systems are currently under clinical trial or being 
extensively studied. Over the last two decades, the number of commercially available nanoparticle based-products has been increasing and by 2006, twenty-four nanotechnology based therapeutic products have been approved for clinical use ${ }^{38}$. Liposomal drugs and polymer drug conjugates account for most of the FDA (Food and Drug Administration, USA) approved systems so $\operatorname{far}^{37}$.

Bleomycin (BLM) is one of the most potent natural anti-tumor drugs and has been used for chemotherapeutic agents in clinical treatments of some cancers, such as Hodgkin's disease, nonHodgkin's lymphoma and testicular cancer ${ }^{39,40}$. The mechanism of this drug is a deoxyribose oxidation that is similar to the free radical damage of DNA by chelating metals ${ }^{27}$. This results in disturbing the normal replication, transcription, and other aspects of DNA metabolism in tumor cells $^{40}$. The therapeutic effectiveness, however, is limited due to the side effects the drug causes, most notably pulmonary toxicity ${ }^{27}$. The usage of this particular antitumor drug could be widened if lower dosages could be delivered closer to the target and could be contained. Several nanoparticle systems had been used in the past for mediated delivery of bleomycin. Georgelin et al. used core-shell magnetic nanoparticles (CSMNs) that consisted of citrate-coated maghemite nanoparticles with a diameter of $7 \mathrm{~nm}$, covered with a silica shell and functionalized with PEG chains. Results from clonogenic assay showed that the cells incorporated with the drug and CSMN had $10 \%$ clonogenic efficiency, while cells incorporated with the CSMNs only were able to reproduce normally at a $90 \%$ clonogenic efficiency ${ }^{27}$. The hydrodynamic diameter of the whole bleomycin and CSMN complex was measured to be $40 \mathrm{~nm}$ but the complex was observed in the nucleus through $\mathrm{TEM}^{27}$. Noting that the CSMN has no known nuclear targeting properties, this indicates that the bleomycin might have properties that allow itself to enter the nucleus. Having nuclear targeted carriers could further translocate the complex to the nucleus possibly at 
a lower dosage. Jain et al. used bleomycin as a radiomimetic agent and observed survival fraction (SF) was 0.39 in cells exposed to GNPs before the bleomycin exposure, which was close to a two-fold decrease than the SF of 0.62 for the bleomycin-only controls ${ }^{41}$.

Another successful anticancer drug that is widely used today is cisdiamminedichloroplatinum(II), also known as $\operatorname{cisplatin}^{42}$. Cisplatin has been known since 1845 , its antitumor activity was established in 1970, and was approved by the FDA in $1978^{43-46}$. Cisplatin is used to treat ovarian, cervical, head and neck, esophageal, and non-small cell lung cancers, but especially the cure rate of testicular cancer reaches over $90 \%{ }^{47-51}$. Although promising clinical trial results has been proven, one of the major side effects that come with cisplatin is severe renal toxicity ${ }^{52}$. Hydration therapy and diuresis is used to overcome this drawback $^{52}$. The uptake pathway of this drug is known to be through passive diffusion as the uptake is not dependent on $\mathrm{pH}$ and it is not inhibited by structural analogues ${ }^{53}$. Once cisplatin is injected to the bloodstream, the high concentration of chloride ions (100 mM) suppresses hydrolysis, allowing cisplatin to remain in a neutral state. Once the drug is diffused into the cell, the lower chloride concentration $(20 \mathrm{mM})$ facilitates hydrolysis, transforming the drug into an active form and allowing it to react with cellular targets ${ }^{53}$. It is generally accepted that the primary target for cisplatin is the DNA by forming a cisplatin - DNA cross-link structure, resulting in distortion of the DNA ${ }^{42,54,55}$. The formation of this cross-link structure destroys the helix stability of the $\mathrm{DNA}^{42}$. Since DNA replication and transcription are essential for cell division and protein production, the cisplatin binding to the DNA and distorting the DNA structure and interfering with normal functioning of this important cellular component would be considered cytotoxic ${ }^{42}$. Some studies showed that cisplatin inhibits DNA transcription, where transcription refers to the process where mRNA is produced from a DNA template. This cellular 
process is critical in protein synthesis ${ }^{56,57}$. In these studies, cisplatin-treated cells progressed through the S phase of the cell cycle, where DNA synthesis happens and arrested in the G2 phase, the gap 2 phase which is the second gap between the synthesis and mitosis. For cells treated with lower concentration of cisplatin, the G2 arrest was temporary. However, for cells treated with higher concentrations remained in the G2 arrest until cell death occurred ${ }^{56}$. The mechanism of cell death from cisplatin was found to be through apoptosis ${ }^{58}$. Apoptosis, which is also known as 'programmed cell death' is characterized by cell shrinkage and surface blebbing which was observed in Sorenson's study ${ }^{58}$. One of the main reasons for cisplatin treatment failure pertains to resistance to the drug. The resistance is either intrinsic to certain cells or acquired through exposure to the compound ${ }^{42}$. Several studies have been performed to understand the mechanism of resistance, but contradictory results have been found. Multiple mechanisms have been identified for cisplatin resistance, which include changes in intracellular accumulation of the drug, increased production of intracellular thiols to modulate toxicity, and increased capability of cells to repair damage from the cisplatin-DNA crosslinkage ${ }^{42}$.

Using nuclear targeted GNPs as a vector for antitumor drugs that are currently in use today, such as bleomycin and cisplatin, could possibly carry the drugs into the target area and therefore improve bioavailability of the drug. This will improve therapeutics by lowering the dosage and lowering side effects. 


\subsection{Combinational radiation and drug therapeutics}

\section{Potential future studies}

A potential future study can be proposed based on the results of this current project and expanding the objectives to include broader aspects. Incubating spherical GNPs conjugated with specific type of peptide sequences increased the uptake into the cell and improved on the intracellular retention and was successful in targeting to the nucleus of HeLa cells, a human cervical cancer cell line. Irradiation was performed and resulted in increased therapeutics upon nuclear targeting.

Examples of prospective studies that could expand on the platform built from this project are:

- To find optimal ratio and sequences for nuclear targeting specific to different cell lines

- To combine use of peptide-conjugated GNPs with therapeutic drugs to improve treatment results or to have effective treatment results with lower dosages. The treatment system could be possibly combined with radiation therapy to further include additional therapy methods.

GNPs in combination with radiations and chemotherapeutic drugs can provide interesting avenues to further improve the treatment of cancer. Based on this study, it can be concluded that it is feasible to develop a NP-based multifunctional system for engineering a more aggressive and effective approach in eradicating cancer. 


\subsection{References}

1. Das IJ, Chopra KL. Backscatter dose perturbation in kilovoltage photon beams at high atomic number interfaces. Med Phys. 1995;22(6):767-773.

2. Das IJ. Forward dose perturbation at high atomic number interfaces in kilovoltage x-ray beams. Med Phys. 1997;24(11):1781-1787.

3. Allal AS, Richter M, Russo M, Rouzaud M, Dulguerov P, Kurtz JM. Dose variation at bone/titanium interfaces using titanium hollow screw osseointegrating reconstruction plates. Int J Radiat Oncol Biol Phys. 1998;40(1):215-219.

4. Melian E, Fatyga M, Lam P, et al. Effect of metal reconstruction plates on cobalt-60 dose distribution: A predictive formula and clinical implications. Int J Radiat Oncol Biol Phys. 1999;44(3):725-730.

5. Cho SH. Estimation of tumour dose enhancement due to gold nanoparticles during typical radiation treatments: A preliminary monte carlo study. Phys Med Biol. 2005;50(15):N163-73.

6. Li XA, Chu JC, Chen W, Zusag T. Dose enhancement by a thin foil of high-Z material: A monte carlo study. Med Phys. 1999;26(7):1245-1251.

7. Chithrani DB, Jelveh S, Jalali F, et al. Gold nanoparticles as radiation sensitizers in cancer therapy. Radiat Res. 2010;173(6):719-728.

8. Rahman WN, Bishara N, Ackerly T, et al. Enhancement of radiation effects by gold nanoparticles for superficial radiation therapy. Nanomedicine. 2009;5(2):136-142.

9. Santos Mello R, Callisen H, Winter J, Kagan AR, Norman A. Radiation dose enhancement in tumors with iodine. Med Phys. 1983;10(1):75-78. 
10. Nath R, Bongiorni P, Rockwell S. Iododeoxyuridine radiosensitization by low- and high-energy photons for brachytherapy dose rates. Radiat Res. 1990;124(3):249-258.

11. Kim D, Park S, Lee JH, Jeong YY, Jon S. Antibiofouling polymer-coated gold nanoparticles as a contrast agent for in vivo X-ray computed tomography imaging. J Am Chem Soc. 2007;129(24):76617665.

12. Haller C, Hizoh I. The cytotoxicity of iodinated radiocontrast agents on renal cells in vitro. Invest Radiol. 2004;39(3):149-154.

13. Hizoh I, Haller C. Radiocontrast-induced renal tubular cell apoptosis: Hypertonic versus oxidative stress. Invest Radiol. 2002;37(8):428-434.

14. Regulla DF, Hieber LB, Seidenbusch M. Physical and biological interface dose effects in tissue due to X-ray-induced release of secondary radiation from metallic gold surfaces. Radiat Res. 1998;150(1):92100.

15. Herold DM, Das IJ, Stobbe CC, Iyer RV, Chapman JD. Gold microspheres: A selective technique for producing biologically effective dose enhancement. Int J Radiat Biol. 2000;76(10):1357-1364.

16. Hainfeld JF, Slatkin DN, Smilowitz HM. The use of gold nanoparticles to enhance radiotherapy in mice. Phys Med Biol. 2004;49(18):N309-15.

17. Chithrani BD, Chan WC. Elucidating the mechanism of cellular uptake and removal of protein-coated gold nanoparticles of different sizes and shapes. Nano Lett. 2007;7(6):1542-1550.

18. Chithrani BD, Ghazani AA, Chan WC. Determining the size and shape dependence of gold nanoparticle uptake into mammalian cells. Nano Lett. 2006;6(4):662-668. 
19. Connor EE, Mwamuka J, Gole A, Murphy CJ, Wyatt MD. Gold nanoparticles are taken up by human cells but do not cause acute cytotoxicity. Small. 2005;1(3):325-327.

20. Lewinski N, Colvin V, Drezek R. Cytotoxicity of nanoparticles. Small. 2008;4(1):26-49.

21. Matsudaira H, Ueno AM, Furuno I. Iodine contrast medium sensitizes cultured mammalian cells to X rays but not to gamma rays. Radiat Res. 1980;84(1):144-148.

22. Norman A, Ingram M, Skillen RG, Freshwater DB, Iwamoto KS, Solberg T. X-ray phototherapy for canine brain masses. Radiat Oncol Investig. 1997;5(1):8-14.

23. Shukla R, Bansal V, Chaudhary M, Basu A, Bhonde RR, Sastry M. Biocompatibility of gold nanoparticles and their endocytotic fate inside the cellular compartment: A microscopic overview. Langmuir. 2005;21(23):10644-10654.

24. Unezaki S, Maruyama K, Hosoda J, et al. Direct measurement of the extravasation of polyethyleneglycol-coated liposomes into solid tumor tissue by in vivo fluorescence microscopy. Int $J$ Pharm. 1996;144(1):11-17.

25. Jain RK. Transport of molecules, particles, and cells in solid tumors. Annu Rev Biomed Eng. 1999;1(1):241-263.

26. Helm E. Nanotechnology may replace existing treatments for cancer. Eukaryon . 2007.

27. Georgelin T, Bombard S, Siaugue J, Cabuil V. Nanoparticle-Mediated delivery of bleomycin. Angewandte Chemie. 2010;122(47):9081-9085.

28. Strebhardt K, Ullrich A. Paul ehrlich's magic bullet concept: 100 years of progress. Nat Rev Cancer. 2008;8(6):473-480. 
29. Gullotti E, Yeo Y. Extracellularly activated nanocarriers: A new paradigm of tumor targeted drug delivery. Mol pharm. 2009;6(4):1041-1051.

30. Vincent A, Babu S, Heckert E, et al. Protonated nanoparticle surface governing ligand tethering and cellular targeting. ACS nano. 2009;3(5):1203-1211.

31. Emerich DF, Thanos CG. Targeted nanoparticle-based drug delivery and diagnosis. J Drug Target. 2007;15(3):163-183.

32. Groneberg DA, Giersig M, Welte T, Pison U. Nanoparticle-based diagnosis and therapy. Curr Drug Targets. 2006;7(6):643-648.

33. Davis ME. Nanoparticle therapeutics: An emerging treatment modality for cancer. Nat rev Drug discov. 2008;7(9):771-782.

34. Duncan B, Kim C, Rotello VM. Gold nanoparticle platforms as drug and biomacromolecule delivery systems. J Control Release. 2010;148(1):122-127.

35. Ferrari M. Cancer nanotechnology: Opportunities and challenges. Nature Reviews Cancer. 2005;5(3):161-171.

36. Lavan DA, McGuire T, Langer R. Small-scale systems for in vivo drug delivery. Nat Biotechnol. 2003;21(10):1184-1191.

37. Zhang L, Gu FX, Chan JM, Wang AZ, Langer RS, Farokhzad OC. Nanoparticles in medicine: Therapeutic applications and developments. Clin Pharmacol Ther. 2008;83(5):761-769.

38. Wagner V, Dullaart A, Bock AK, Zweck A. The emerging nanomedicine landscape. Nat Biotechnol. 2006;24(10):1211-1217. 
39. Umezawa Y, Morishima H, Saito S, et al. Synthesis of the pyrimidine moiety of bleomycin. J Am Chem Soc. 1980;102(21):6630-6631.

40. Hecht SM. The chemistry of activated bleomycin. Acc Chem Res. 1986;19(12):383-391.

41. Jain S, Coulter JA, Hounsell AR, et al. Cell-specific radiosensitization by gold nanoparticles at megavoltage radiation energies. Int J Radiat Oncol. 2011;79(2):531-539.

42. Jamieson ER, Lippard SJ. Structure, recognition, and processing of cisplatin-DNA adducts. Chem Rev. 1999;99(9):2467-2498.

43. Lippard SJ. New chemistry of an old molecule: Cis-[pt(NH3)2Cl2. Science. 1982;218(4577):10751082.

44. Rosenberg B, VanCamp L, Trosko JE, Mansour VH. Platinum compounds: A new class of potent antitumour agents. Nature. 1969;222(5191):385-386.

45. Rosenberg B, VanCamp L. The successful regression of large solid sarcoma 180 tumors by platinum compounds. Cancer Res. 1970;30(6):1799-1802.

46. Kociba RJ, Sleight SD, Rosenberg B. Inhibition of dunning asc itic leukemia and walker 256 carcinosarcoma with cis-diamminedichloroplatinum (NSC-119875). Cancer Chemother Rep. 1970;54(5):325-328.

47. Keys HM, Bundy BN, Stehman FB, et al. Cisplatin, radiation, and adjuvant hysterectomy compared with radiation and adjuvant hysterectomy for bulky stage IB cervical carcinoma. $N$ Engl J Med. 1999;340(15):1154-1161.

48. Loehrer PJ, Einhorn LH. Drugs five years later. cisplatin. Ann Intern Med. 1984;100(5):704-713. 
49. Morris M, Eifel PJ, Lu J, et al. Pelvic radiation with concurrent chemotherapy compared with pelvic and para-aortic radiation for high-risk cervical cancer. N Engl J Med. 1999;340(15):1137-1143.

50. Rose PG, Bundy BN, Watkins EB, et al. Concurrent cisplatin-based radiotherapy and chemotherapy for locally advanced cervical cancer. N Engl J Med. 1999;340(15):1144-1153.

51. Bosl GJ, Motzer RJ. Testicular germ-cell cancer. N Engl J Med. 1997;337(4):242-253.

52. Hayes DM, Cvitkovic E, Golbey RB, Scheiner E, Helson L, Krakoff IH. High dose cis-platinum diammine dichloride: Amelioration of renal toxicity by mannitol diuresis. Cancer. 1977;39(4):1372-1381.

53. Andrews PA, Velury S, Mann SC, Howell SB. Cis-diamminedichloroplatinum(II) accumulation in sensitive and resistant human ovarian carcinoma cells. Cancer Res. 1988;48(1):68-73.

54. Cohen GL, Bauer WR, Barton JK, Lippard SJ. Binding of cis- and transdichlorodiammineplatinum(II) to DNA: Evidence for unwinding and shortening of the double helix. Science. 1979;203(4384):1014-1016.

55. Macquet J, Butour J. Modifications of the DNA secondary structure upon platinum binding: A proposed model. Biochimie. 1978;60(9):901-914.

56. Sorenson CM, Eastman A. Influence of cis-diamminedichloroplatinum(II) on DNA synthesis and cell cycle progression in excision repair proficient and deficient chinese hamster ovary cells. Cancer Res. 1988;48(23):6703-6707.

57. Sorenson CM, Eastman A. Mechanism of cis-diamminedichloroplatinum(II)-induced cytotoxicity: Role of G2 arrest and DNA double-strand breaks. Cancer Res. 1988;48(16):4484-4488.

58. Sorenson CM, Barry MA, Eastman A. Analysis of events associated with cell cycle arrest at G2 phase and cell death induced by cisplatin. J Natl Cancer Inst. 1990;82(9):749-755. 